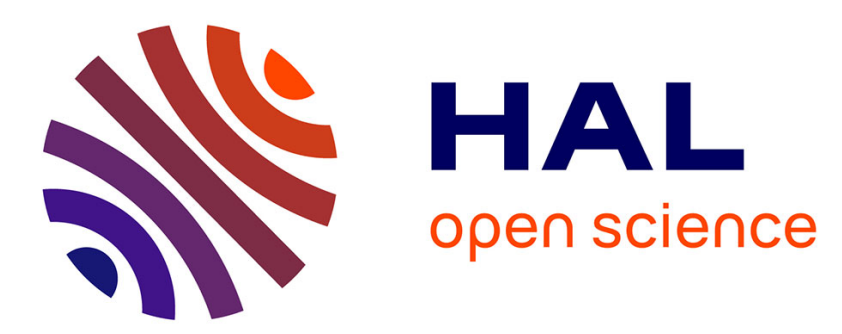

\title{
Bach, Mozart, and Beethoven: Sorting piano excerpts based on perceived similarity using DiSTATIS
}

Rachna Raman, Michael Kriegsman, Hervé Ha Abdi, Barbara Tillmann, W. Jay Dowling

\section{To cite this version:}

Rachna Raman, Michael Kriegsman, Hervé Ha Abdi, Barbara Tillmann, W. Jay Dowling. Bach, Mozart, and Beethoven: Sorting piano excerpts based on perceived similarity using DiSTATIS. New Ideas in Psychology, 2020, 57, pp.100757. 10.1016/j.newideapsych.2019.100757 . hal-02378151

\section{HAL Id: hal-02378151 \\ https://hal.science/hal-02378151}

Submitted on 10 Nov 2020

HAL is a multi-disciplinary open access archive for the deposit and dissemination of scientific research documents, whether they are published or not. The documents may come from teaching and research institutions in France or abroad, or from public or private research centers.
L'archive ouverte pluridisciplinaire $\mathbf{H A L}$, est destinée au dépôt et à la diffusion de documents scientifiques de niveau recherche, publiés ou non, émanant des établissements d'enseignement et de recherche français ou étrangers, des laboratoires publics ou privés. 
Running head: SORTING PIANO EXCERPTS USING DiSTATIS

Bach, Mozart, and Beethoven:

Sorting Piano Excerpts based on Perceived Similarity Using DiSTATIS

Rachna Raman ${ }^{1}$, Michael A. Kriegsman ${ }^{1}$, Hervé Abdi ${ }^{1}$, Barbara Tillmann ${ }^{2}$, \& W. Jay Dowling ${ }^{1}$

${ }^{1}$ The University of Texas at Dallas

${ }^{2}$ Lyon Neuroscience Research Center, Lyon, France

Correspondence concerning this article should be addressed to:

Dr. Rachna Raman

The University of Texas at Dallas,

800 W. Campbell Road,

Richardson, Texas 75080-3021.

rachnaraman@hotmail.com 
1

2 Sorting tasks can reveal the underlying intuitive structure of a collection of items, in this case musical excerpts. Sorting tasks can be used to compare experts and non-experts without relying on specialized vocabulary, and they tend not to fatigue participants. Here, we used the sorting technique with excerpts from the piano music of Bach, Mozart, and Beethoven. Experiment 1 involved sorting $21 \mathrm{MIDI}$-generated stimuli. Experiment 2 utilized 36 excerpts from recorded performances of four pianists (Arrau, Barenboim, Pirès, and Richter). Each experiment involved 2 parts: In Part 1, participants sorted excerpts freely into any number of clusters. In Part 2, participants sorted excerpts into 3 clusters according to whether a single composer could have written the pieces in the group. We divided participants into 3 groups based on music training. We investigated the effects of composer, pianist (in Experiment 2), and music training on sorting. To analyze the data, we applied DiSTATIS, a recent adaptation of multi-dimensional scaling specifically adapted to reveal the perceived dissimilarity among items, as well as to investigate group differences. The results showed an effect of composer in both experiments: In Experiment 1, participants were able to strongly differentiate Beethoven's excerpts from those of the other 2 composers. In Experiment 2, they differentiated Mozart's excerpts from Beethoven's, with Bach falling in between those two. In Experiment 2, participants' sorting decisions were strongly influenced by pianists. Richter's performances of the 3 composers were clustered relatively close to the Mozart region of the solution, indicating their clarity and balance; in contrast, those of Barenboim were clustered in the Beethoven region, indicating their sumptuousness and passion. Training effects were not strong and the highest and lowest expertise groups were differentiated only in the free sorting task of Experiment 2.

Key Words: constrained sorting, free sorting, musical style, musical training, style perception. 


\section{Musical Style and its Perception}

Research on the cognitive processing of musical style is now common in the field of music perception and cognition (e.g., Atalay \& Placek, 1997; Crump, 2002; Dalla Bella \& Peretz, 2005; Eastlund, 1992; Eerola, Järvinen, Louhivuori, \& Toiviainen, 2001; Gardner, 1973;

Gingras, Lagrandeur-Ponce, Giordano, \& McAdams, 2011; Gromko, 1993; Hargreaves \& North, 1999; Miller, 1979; Storino, Dalmonte, \& Baroni, 2007; Tekman \& Hortaçsu, 2002; Thorisson, 1998; Tyler, 1946; Wedin, 1969; Zivic, Shifres, \& Cecchi, 2013). However, earlier research has not yet provided satisfactory answers about the processes underlying style perception. For instance, what features of musical style do listeners perceive in order to categorize the excerpts? Musical style is a complex concept for which a wide range of descriptions has been proposed. Musical style has been defined as a "distinguishing and ordering concept" that "groups examples of music according to similarities between them" (Pascall, 1980). Cope (1991) later defined musical style as “the identifiable characteristics of a composer's music which are recognizably similar from one work to another." Dalla Bella and Peretz (2005) more recently described musical style as that which could refer to a particular musical language (e.g., tonal vs. atonal), to the music composed within a particular historical era (e.g., baroque vs. classical), or to a particular composer's technique (e.g., Mozart's vs. Beethoven's). The defining characteristics of style include recurring phrases, specific forms, melodic, harmonic, or rhythmic features, timbre, typical textures, and formal organization (Meyer, 1973; Vignal, 1987). For instance, Gundlach's (1932) study on the analysis of native American music emphasized the importance of rhythm in categorizing music based on style.

Gardner (1973) defined style recognition as "a complex cognitive process which demands monitoring of numerous aspects of a stimulus, avoidance of over-emphasis upon a 
24 single facet, and attention to the general expressive features of the work." Musical style

25 perception can be seen as one example of sophisticated implicit learning processes that lead to nonverbal knowledge just by mere exposure to individual items. Comparable to implicit learning of language or tonal music, listeners seem to become sensitive to structural regularities underlying style (Agres, Abdallah, \& Pearce, 2018; Raman \& Dowling, 2016; Raman \& Dowling, 2017). Although listeners clearly differ in expertise in doing musical tasks related to musical style, such as identifying musical style based on composer or performer, they also share a lot of commonalities in music perception (e.g., Bigand \& Poulin-Charronnat, 2006; Gingras et al., 2011; Raman \& Dowling, 2017). Daily activities further suggest that listeners, both trained and untrained, are highly sophisticated in recognizing musical styles. For instance, when turning on the radio and listening to music, listeners show remarkable consistency in guessing its musical style (e.g., classical, country, or rock music) or even evaluate finer stylistic differences (e.g., baroque, classical, or romantic periods). And listeners can even easily describe musical excerpts of various styles using similar adjectives (e.g., Hevner, 1936; Miller, 1979; Tekman \& Hortaçsu, 2002; Watt \& Ash, 1998) and open-ended written descriptions (e.g., Dibben, 2001; Morrison \& Yeh, 1999; Thorisson, 1998). Despite the apparent ease of perceptual classification, determining how listeners make such nuanced judgements of style is elusive. As Crump (2002) surmised, an important issue here is to determine the low-level perceptual and high-level abstract information (i.e., cues) that listeners perceive and respond to so as to make judgements of musical style. As early as Hevner (1936), studies have shown that some of the primary features that listeners seem to focus on in understanding a musical piece include mode (major vs. minor), harmony, and rhythm. Musical style, and its perception, thus creates a puzzle: Listeners easily and rapidly recognize the style of an historical period or of a composer, but researchers have 
47 been largely unsuccessful at providing theoretical descriptions that capture the characteristics of musical style and its perception.

Musical style perceptions are also influenced by listeners' music training and general music listening experiences. Meyer (1989) stated that perception of style seems to be a learned

51 behavior for musically trained listeners, which is the case since understanding the chronological 52 development of various musical styles is a necessary part of their music education. For instance, 53 Miller (1979) found that untrained participants tended to focus more on affective qualities of the 54 music (e.g., playful, carefree, pleasing, etc.), whereas expert participants focused more on 55 musical structure and other technical aspects (e.g., form, dynamics, harmony, etc.). Miller also identified an historical dimension but only for the experts, who were able to categorize styles

57 mostly through differences in composers' use of harmony. On the contrary, several other studies 58 have shown that music novices (e.g., Thorisson, 1998; Tyler, 1946; Wedin, 1969) and 59 nonmusicians (e.g., Eastlund, 1992; Gingras et al., 2011; Gromko, 1993), and even non-Western 60 nonmusicians are sensitive to style recognition (e.g., Dalla Bella \& Peretz, 2005), and that

61 perhaps such sensitivity is developed merely due to prolonged exposure to any type of music and 62 the perception of low-level musical cues. In understanding listeners' style perceptions, one particular area of interest is how

64 listeners categorize musical pieces based on stylistic aspects into various genres, such as folk, 65 classical, popular, and so forth. Most of the studies in the field have investigated style perception 66 either via ethnomusicology, wherein researchers quantitatively analyze the prototypical melodies 67 of a particular style of music by studying the statistical distribution of different intervals, pitches, 68 or temporal patterns (e.g., Gundlach, 1932; Zivic et al., 2013), or via the use of trained computer 69 networks and simulations to imitate human performance (e.g., Järvinen, Toiviainen, \& 
71

72

Louhivuori, 1999; Smaill \& Westhead, 1993). Some researchers have even compared computer simulations versus human performance on style identification and categorization (e.g., Atalay \& Placek, 1997; Crump, 2002; Tillmann, Abdi, \& Dowling, 2004). Through such analyses, researchers have systematically examined both low-level perceptual characteristics, such as statistical patterns of notes, and high-level abstract features, such as harmony, rhythm, and melody, of music that contribute towards style perception.

Studies using sorting tasks, which are implicit and do not require verbalization of stylistic features by human listeners, are relatively rare, mostly due to the difficulty in finding suitable methods to accurately measure listeners' perception of style. Earlier studies mostly relied on tasks where participants had to explicitly verbalize their judgements of style (e.g., Tyler, 1946; Gardner, 1973). One of the earliest studies on style perception was conducted by Tyler (1946), who had novice music students listen to 3-min excerpts of three selections each from Mozart, Beethoven, and Schubert. These excerpts were from different movements within the same piece. The stimuli were presented randomly and the students had to verbally judge who the composer of each selection was. The study was performed twice by the same participants on two different occasions during the semester. The results indicated that on both occasions participants showed sensitivity to style recognition, and this sensitivity was related to their prior music training and concert experience, but not with their intelligence scores or their preference of the composers or music pieces.

Gardner (1973) conducted a developmental investigation of style, and the obtained data from a verbalization task showcased the importance of participant age in musical style perception. Five groups of participants (ages 6, 8, 11, 14, and $18-19$ years) judged whether pairs of 15-s excerpts of classical music from 1680 to 1960 belonged to the same piece or not. 
93 Participants 11 years and older performed similarly and more accurately than the younger

94 participants, who also showed some sensitivity to such discriminations. Also, participants 11

95 years and older could discriminate pieces based on subtler aspects of style, and were able to

96 categorize the pieces as either from the same musical era or from different eras.

97

98

99

100

101

102

103

104

105

106

107

108

109

110

111

112

113

114

115

With advancement in statistical methods, researchers began using nonverbal "rating" tasks, such as the similarity-judgement task, and multidimensional scaling (MDS) to analyze subjective ratings, thus popularizing its application to investigate recognition of musical style.

The similarity-judgement task involves nonverbal categorization of musical stimuli via rating responses. For instance, Wedin (1969) investigated the perceptual dimensions into which the historical epochs of music would fall using MDS. Participants heard 98 pairs of 10-s excerpts (including repetitions) of Western classical music from 1720 to 1890, and rated them in two types of similarity-judgement tasks. In the first task, novices with less than 5 years of music training judged the degree of similarity in percentage between pairs of excerpts. In the second task, a similar procedure was followed and three participant groups (highly and moderately trained groups, and novices) had to rate on a 10-point scale the subjective similarity in style of the pair of excerpts. The results revealed that all participants showed style sensitivity but participants with greater musical training grouped the musical excerpts into four distinct clusters-Baroque, Rococo, Viennese Classicism, and Romanticism. Thus, they showed a clearer and nuanced distinction among the categories. On the contrary, participants with lesser or no musical training grouped the musical excerpts into three distinct clusters-Baroque, Viennese Classicism, and Romanticism.

Eastlund (1992; also Gromko, 1993) further extended this approach using the same nonverbal task to investigate differences in style perception among untrained participants, music 
116

117

118

119

120

121

122

123

124

125

126

127

128

129

130

131

132

133

134

135

136

137

undergraduates, and experts (music professors). She used 15 musical pieces belonging to either the classical or the romantic styles, composed between 1762 and 1896. Participants heard 105 pairings of 15-s music excerpts and performed a similarity-judgement task using a 7-point scale. MDS analysis showed that music undergraduates and expert musicians performed almost identically, and their combined responses could be classified into three dimensions (in order of importance): historical period in which the piece was composed, perceived complexity of the excerpt, and its tempo. On the contrary, for untrained participants historical period was the least important, which partially explains Miller's (1979) findings of a lack of historical dimension for untrained participants. Eastlund proposed an explanation for this difference in style perception, that untrained participants may focus more on what she called secondary features of music (e.g., tempo, pitch, dynamics, etc.), whereas trained participants focus more on primary features (e.g., melody, harmony, etc.).

Later, Thorisson (1998) examined the validity of style-categorization results from the nonverbal similarity-judgement task by comparing with participants' open-ended written descriptions. He examined whether novice listeners were able to classify musical excerpts as either classical or romantic, based on compositional styles. Participants were first familiarized with 17 classical and romantic piano excerpts, and then they completed similarity ratings of the 136 possible pairings of the excerpts. MDS indicated that the excerpts were generally grouped into two clusters, one for the classical period and the other for the romantic era. Listeners gave written descriptions of attributes pertaining to texture, tempo, dynamics, and so forth, for each piece, and the results showed that excerpts from the same musical period but by different composers received similar attributes, thus validating the use of both tasks. 

157 style.

Several studies have used the nonverbal similarity-judgement task to determine the exact nature of the musical cues listeners employ to identify the genre of a musical piece. For example, Eerola, Järvinen, Louhivuori, and Toiviainen (2001) used similarity ratings of folk melodies to predict music students' classification of melodies that represented five different European folk styles. MDS analysis showed that the students were able to categorize the melodies based on the different folk styles. The results also indicated that the salient aspects of a musical piece, such as statistical properties of the pitches and rhythm, to which listeners generally paid attention, presumably helped listeners classify the pieces according to melodic similarity.

Supplementing Eerola et al.’s (2001) findings, Tekman and Hortaçsu (2002) used a verbalization task to determine how listeners perceived the relationship among various musical styles. They asked Turkish undergraduate students to list all the genres of music they knew and had them rate a list of adjectives on how appropriately they described each genre. MDS identified two components based on the students' classification of the different styles: historical novelty (traditional vs. modern) and appeal (to large population vs. to small groups) of the styles. The students classified closely associated styles, such as rap and techno, systematically. Qualitative analyses showed that the students also described the musical styles on the basis of three dimensions - evaluative, activity, and peacefulness. Tekman and Hortaçsu's study provided evidence that listeners not only possess knowledge on various styles of music but also on the relationship of the styles to each other, and the unique descriptive qualities associated with each different approach with the same nonverbal similarity-judgement task. They had two professional composers create 16 piano excerpts imitating the musical styles of baroque, 
161 classical, romantic, and post-romantic eras, and six advanced piano students recorded the excerpts. Each student played excerpts from only one style so that confusion between compositional styles and performance styles could be avoided. Since the excerpts were

164 composed specifically for the study, the researchers could control for confounds (e.g., familiarity with the musical piece). Western music students, and Western and non-Western (Chinese) nonmusic students performed a familiarity-rating task for each excerpt and a similarity-judgement 167 task for 128 excerpt pairs. Half of the excerpt pairs were presented in the historical order (e.g., 168 classical followed by post-romantic) whereas the other half of the pairs were presented in the 169 inverse order (e.g., post-romantic followed by classical). MDS analysis showed that all participants rated melodies from earlier historical periods (e.g., baroque) as more familiar, and 171 they rated compositions closer in styles (i.e., historical eras) as similar. This sensitivity to style 172 recognition was enhanced in the musician group, though both Western and non-Western 173 nonmusician groups also showed an obvious sensitivity, indicating the significance of mere 174 passive long-term exposure to music. Dalla Bella and Peretz also proposed that universal low175 level perceptual processes (such as, temporal regularities) may underlie style sensitivity. And 176 finally, the results showed an order effect, wherein participants differentiated the styles more 177 easily when the excerpts were presented in chronological order rather than when reversed. 178 Storino, Dalmonte, and Baroni (2007) further extended Dalla Bella and Peretz's (2005) 179 research by investigating whether familiarization with a single composer's musical grammar can 180 facilitate listeners' style categorization based on that composer's technique and of the 181 corresponding historical period in general. In Experiment 1, expert musicians in the baroque 182 style were first familiarized with eight Legrenzi's (an Italian baroque composer) arias. In the test 183 phase, participants heard excerpts from 10 arias by Legrenzi and 10 arias produced by LEGRE (a 
184 185

computer program that produces new arias in Legrenzi's style for the same texts of music). Half of the participants heard the excerpts as 10 Legrenzi-LEGRE pairs and the remaining participants heard the 20 excerpts in isolation (i.e., not paired). Both groups had to identify which of the excerpts was composed by Legrenzi. All participants were able to classify based on style, however, accuracy was higher in the paired condition and was just above chance level in the isolated condition. In Experiment 2, trained (not in any particular style) and untrained participants performed only the paired task. The results showed that only the trained participants were able to perform above chance level. The method of Experiment 4 was the inverse of Experiment 1, wherein trained participants were first familiarized with eight arias produced by LEGRE. In the test phase, they heard only 18 arias by three Italian baroque composersLegrenzi, Rossi, and Gabrielli — and not those produced by LEGRE. Participants had to indicate whether the arias had been created by the same composer in the familiarization phase (i.e., LEGRE) or not, and the results showed that participants were successful, thus confirming the similarity between LEGRE and Legrenzi styles of composition. Storino et al. found that with brief exposure, even musicians non-experts in the baroque style (as in Experiments 2 \& 4) were able to perceive stylistic features of the music.

Storino et al. (2007) used a sophisticated grammar based on musicological analysis in their LEGRE program. A contrasting approach in recent years relies on simply capturing the sequential regularities of the musical style in the music in a Markov-based statistical learning program (see Agres et al., 2018, for a review). Listeners have been shown to extract the sequential regularities of melodies they were exposed to, and expectancies are fairly well matched by the statistical learning programs. However, as Krumhansl (2015) points out, citing Meyer (1989), there is more to musical style and listeners' - even untrained listeners'- 
207

208

209

210

211

212

213

214

215

216

217

218

219

220

221

222

223

224

225

226

227

228

229

understanding of it than can be captured with Markovian statistical learning. Music has structural and expressive properties that are easily grasped by the attentive listener, but which are not taken into account by Markovian statistics.

To summarize, researchers over the years have used various types of verbal and nonverbal tasks in order to ascertain how listeners perceive and categorize stylistic aspects of music. The results show a broad picture that trained and untrained listeners, and even untrained young children, are generally sensitive to stylistic aspects of music, and expertise enhances the perception of style. However, most of the earlier work has only been able to speculate about the types of cues used by trained and untrained listeners in such tasks. One reason is that the types of tasks used in previous studies may not have been suitable to answer the primary question: How do listeners categorize musical excerpts based on stylistic aspects? Studies involving the measurement of implicit processes, such as those applied in the categorization of stimuli, should use appropriate indirect or implicit investigation methods to obtain the best possible results. The sorting task is designed for measuring implicit processes, such as those involved in most musicrelated tasks. For instance, Brown (1981) found that trained and untrained participants agreed less with their group performance when they had to pair melodies with descriptive words provided by the researcher (explicit) versus when they did the matching task by providing their own words (implicit). Similarly, Dibben (2001) found differences in participant responses between nonverbal and verbal categorization tasks, wherein participants were more inclined to group two sounds when they resembled each other acoustically in the implicit nonverbal task, whereas they were more inclined to group them by their physical source in the explicit verbal task. A second reason is that earlier tasks involving style perception and its analyses only provided results obtained by averaging group responses, and there was no way to track 
230 individual responses. This could be due to the fact that the statistical tools used to measure and 231 analyze the multidimensional aspects typically characteristic of human responses were not 232 sophisticated enough, and did not provide the possibility of projecting the results from various 233 perspectives (e.g., composer, participant expertise) into the same space, thus giving a 234 fragmentary account of those perspectives.

The only study we know of that has used a sorting task to categorize musical style (note 236 that here it was not composer's style but performer's style of playing) was conducted by Gingras, 237 Lagrandeur-Ponce, Giordano, and McAdams (2011). Experts and non-experts heard organ 238 excerpts represented as icons on a computer screen, which they had to sort into six groups based 239 on the performer's playing style. The excerpts were played by three award-winning and three 240 non-award-winning organists, who rendered two versions each of expressive and inexpressive 241 interpretation of the same piece. The results indicated that both trained and untrained participants 242 were able to accurately sort excerpts based on tempo, wherein faster excerpts were differentiated 243 from slower excerpts, and articulation (connectedness or separateness of notes in time), wherein 244 expressive performances were differentiated from inexpressive ones. Also, participants' sorting 245 was influenced by performer competence, in that they accurately differentiated between award246 winning versus other performers.

$247 \quad$ Although Gingras et al. (2011) successfully used the sorting task in a well-controlled 248 setting, in which participants heard versions of the same excerpt played in different ways by six 249 organists, an important issue that should be further studied is whether listeners can categorize 250 excerpts of different composers played by different performers based on stylistic features. Also, 251 Gingras et al. only used the constrained sort, which prompted us to investigate whether 
252 participants would be able to categorize by composer's style when they are first told to sort freely

253 into as many groups as they see fit.

254 Goals and Hypotheses

255

256

257

258

259

260

261

262

263

264

265

266

267

268

269

270

271

272

273

274

The purpose of our study was to extend previous findings by examining the influence of compositional style, type of sorting task (i.e., free vs. constrained), type of stimuli (MIDI vs. natural), pianists' playing style, and listeners' music expertise on their ability to perceive stylistic aspects in musical excerpts. We used both free and constrained sorting tasks and an updated version of the statistical tool DiSTATIS, which had never before been used in studies pertaining to music perception and cognition. One advantage of the sorting method is that the judgements are more likely to reflect the multiple dimensions of the stimuli than would have been the case when using the earlier paired comparison similarity judgements. Moreover, sorting tasks do not involve any form of verbalization, thus tapping into the listeners' implicit knowledge. And such a nonverbal approach facilitates the use and assessment of stylistic cues. Our study addressed the following questions: (1) Are listeners able to sort brief melodies based on compositional style? (2) If so, does the type of sorting task - free versus constrained — interact with music expertise in influencing listeners' perception? Investigations involving other features of music, such as emotion (e.g., Bigand, Vieillard, Madurell, Marozeau, \& Dacquet, 2005; Bigand, Filipic, \& Lalitte, 2005), as well as research not involving music (e.g., Scott \& Canter, 1997) have measured listener responses in both sorting tasks while presenting the two tasks sequentially, free sort followed by constrained sort. However, none of the sorting studies pertaining to musical style that we have referenced have tested this, and so we decided to investigate what might prompt differences, if any. Especially, we wanted to examine whether untrained participants in particular could produce coherent categorizations for composer's style with the free sort. (3) 
275 Does the type of stimuli-MIDI versus natural — influence the task? In contrast to the previous 276 studies, we compared listeners' perception of stylistic aspects in music between both MIDI and 277 natural stimuli excerpted from commercial recordings. (4) Also, will the performance of four 278 different pianists influence musical style perception? Unlike Dalla Bella and Peretz (2005), we 279 wanted to examine whether individual playing styles will influence participants' sorting choices 280 and the degree to which the different playing styles would affect listeners' perception of the 281 composers. (5) Finally, does the listener's music training influence the perception of stylistic 282 aspects of music? Based on earlier studies (e.g., Crump, 2002; Dalla Bella \& Peretz, 2005; Eastlund, 1992;

284 Eerola et al., 2001; Gardner, 1973; Gromko, 1993; Hargreaves \& North, 1999; Miller, 1979;

285 Storino et al., 2007; Tekman \& Hortaçsu, 2002; Thorisson, 1998; Tyler, 1946; Wedin, 1969), we 286 hypothesized that there would be an effect of musical period and compositional style, and that 287 listeners would identify greater stylistic differences among pieces from eras farther apart. That is, 288 participants would more distinctly categorize pieces by Bach and Beethoven versus those by 289 Bach and Mozart, or Mozart and Beethoven. Our second hypothesis was that, in general, 290 participants would be faster and more accurate in their perception of style in the constrained sort 291 when compared to the free sort. We based our prediction on the fact that participants completed 292 the constrained sort immediately following the free sort, which made them somewhat more 293 familiar with the excerpts. Also, the instructions were "clearer" with the constrained sort, where 294 we disclosed the actual number of composers. We expect that the results might indicate how far 295 increased familiarity and the change in instruction would change the result pattern. Our third 296 hypothesis was partly based on Gingras et al.'s (2011) findings, that participants would be more 297 accurate at perceiving the stylistic aspects in an expressive performance (natural stimuli) when 
compared to a more mechanical one, since the natural stimuli have richer dynamics and tonal qualities, thus facilitating perception. Our fourth hypothesis was also partly based on Gingras et al.'s (2011) findings, that in Experiment 2, listeners would be influenced by the performance of the pianists in their sorting of the pieces. Thus, composers' style would interact with pianists' style wherein participants might incorrectly attribute pieces to other composers due to confusion with the pianist's performance style. Our last hypothesis was that highly trained musicians would be more accurate than untrained participants at perceiving the stylistic aspects. Previous research has shown that professional musicians perceive musical structures differently from amateur musicians (Dowling, 1986), with experts performing better than amateurs at a variety of musical tasks (Krampe \& Ericsson, 1996). However, several studies have also shown that untrained participants are sensitive to underlying structural and affective patterns of music, and are able to perform several musical tasks above chance levels (e.g., Bigand \& Poulin-Charronnat, 2006; Eastlund, 1992; Dalla Bella \& Peretz, 2005; Gingras et al., 2011; Gromko, 1993; Wedin, 1969). Thus, we also expect that untrained participants would display some style sensitivity.

\section{Framework for Compositional Style}

In this study, we used piano excerpts from three composers: Bach, Mozart, and Beethoven. The composers' compositional styles are classified into three different epochs: Bach's style is classified as baroque, Mozart's as classical, and Beethoven's as romantic. There is general agreement among musicologists that Bach is a prototypical baroque composer who played a very special role in the baroque period (Grout \& Palisca, 1980). Nevertheless, his compositions stood out in the baroque era due to their melodic, harmonic, and rhythmic complexity. In general, though Bach occasionally shifted emotional tone in the middle of a movement (especially in his cantatas), he typically followed the baroque style of maintaining a 
321 constant emotional tone throughout a movement. Composers in the generation after Bach (e.g.,

322 Josef Haydn and Bach's son Carl Philipp Emmanuel), began to experiment with emotional shifts

323 within a movement, techniques that Mozart exploited during the classical period. In Beethoven,

324 the range and frequency of emotional shifts was expanded even further. Beethoven is right at the

325 start of the romantic approach, and his earlier works are usually viewed as transitional between

326 the classical and the romantic.

327

Especially in Experiment 2, we selected almost all of Beethoven's excerpts from his

328 romantic period. In accordance with the main features of musical style outlined above, we can

329 characterize these three styles in terms of the variability of the musical material along the

330 dimensions of pitch, time, and loudness, as well as of musical texture (dense vs. open and

331 transparent) and timbre. Timbre is not so much an issue in the present experiments because all

332 the excerpts are played on the piano, or in a piano timbre. And variations in loudness and tempo

333 are only an issue in Experiment 2 where we used actual performances of the pieces, in contrast to

334 the MIDI transcriptions of Experiment 1 which do not vary in loudness or in tempo. The

335 harmonic language differs among these styles - the way in which chord progressions and key

336 relationships are handled as the music develops in time (e.g., Zivic et al., 2013). Also,

337 Krumhansl (2015) cites results showing that there are differences in interval patterns between

338 baroque (largely scale wise) and romantic (largely arpeggios) styles. And there is a definite

339 change in the variability of emotional tone within an excerpt as we progress through the early

340 (baroque) and the middle (classical) $18^{\text {th }}$ century and then on to the $19^{\text {th }}$ (romantic).

The baroque style exemplified by Bach is characterized by rhythmic regularity as well as

342 relative stability of loudness, pitch, texture, and emotional tone within an excerpt. The harmonic

343 language is dense and complicated, taking surprising turns which are then resolved to achieve 
344 expected ends. The texture typically consists of the interweaving of two or three separate 345 melodic lines in different pitch registers, which are clearly discernable. This is in contrast, for example, to music that consists of a single melodic line accompanied by block chords in which

347 the individual pitches are not distinctly heard.

The classical style emerged from the baroque through the innovations of mid-

century composers, such as C.P.E. Bach, Haydn, and Mozart. The harmonic language becomes simpler, often with a slower progression from chord to chord, but shifts of tonal center (modulations) are often more abrupt, and signal a shift in emotional tone. Rhythmic organization also becomes more irregular than in the baroque, accompanied by greater variation in loudness. Textures are more varied, with dense as well as open textures, and often with a single melodic 354 line with chords or repetitive melodic figures outlining chords as accompaniment. tendencies apparent in classical music become accentuated. Especially for Beethoven (in contrast 357 to later romantics, such as Chopin, Schumann, and Brahms), the harmonic language becomes even more simplified. Beethoven is sometimes inclined to emotional outbursts indicated by 359 abrupt changes in loudness, tempo, and texture. The range of pitches typically in use, expanded somewhat in the classical compared with the baroque, is now widely expanded.

362 their influence on each other is one-directional. Mozart was a dedicated admirer of Bach, and 363 from time to time there are unmistakable signs of Bach's influence. Mozart's String Trios, K. $364404 \mathrm{a}$, consists of his arrangements of Bach preludes and fugues, along with additional pieces to 365 go with them that he wrote in the same style. And the duet for the Two Armed Men in The 366 Magic Flute is definitely written in the style of Bach, which gives it a seriousness and solemnity 
367 important to that scene in the opera. And Beethoven drew on both Bach and Mozart in his piano

368 music and string quartets, in which he includes passages where the interweaving of simultaneous

369 melodic lines is reminiscent of Bach. Beethoven was fond of Mozart's piano concertos,

370 especially Concerto No. 20 in d minor, which he often played in concerts and for which he wrote

371 a cadenza.

372 Framework for Pianist Style

373

Whereas in Experiment 1 we used MIDI transcriptions that simply reproduced the notes

374 on the printed page with no stylistically induced nuances in performance, such as variations in

375 loudness, tempo, and phrasing, in Experiment 2 we used excerpts from commercial recordings

376 played by four pianists: Claudio Arrau, Daniel Barenboim, Maria-João Pirès, and Sviatislav

377 Richter. We picked these pianists because they were among the relatively few pianists in the

378 middle and late $20^{\text {th }}$ century who had recorded substantial amounts of the works of the three

379 composers. (Many pianists are known for concentrating on one composer, or several composers

380 in a similar stylistic period. Arthur Rubenstein, known for Beethoven and the later romantics, for

381 example, rarely if ever recorded Bach or Mozart, and Rosalyn Tureck, a Bach specialist, rarely

382 recorded Mozart or Beethoven.) We also selected them because their personal styles of playing

383 the piano differed systematically. Richter is widely regarded as presenting each composer, and

384 each piece, in its own terms, without imposing a particular personal imprint, but with

385 considerable emotional engagement (Villemin, 1999). His Bach is transparent and lucid, in that

386 the inner melodic lines are rarely obscured, but it is also forceful, as are his Mozart and

387 Beethoven. Arrau has been described as leaving his own imprint on the pieces he engages with

388 (Villemin, 1999), but his Bach is also transparent and his emotional engagement is very clear. In

389 contrast to Richter's playing which can often strike one as jagged and craggy, Arrau's is much 
390

391

smoother, but equally sensitive to the emotional tension. Pirès has a much lighter touch than either Richter or Arrau - transparent and lucid with all three composers, and often more playful. Barenboim - and here we are talking of the Barenboim of the 1960s and 70s, and not the mature Barenboim evident in his recordings during the last 10 years — definitely leaves his own imprint on all the pieces, and it is an imprint most suited to the highly emotional Beethoven. He uses the sustain pedal of the piano much more than the other pianists, which aids in the buildup of emotional climaxes, but inhibits transparency in open textures, such as those of Bach and Mozart.

In our two experiments, undergraduate and graduate students from an American university participated in the study. All participants reported having normal hearing and a regular school education of at least 12 years. We obtained informed consent from each participant before the start of the experiment, and all participants completed a brief questionnaire on their musical experience. Participants included musicians at various levels of training (as measured by years of formal training).

\section{Experiment 1: MIDI stimuli}

\section{Method}

Participants. Thirty-nine participants, mean age 22.47 years (range $=18$ to 29 years), took part in Experiment 1. Eleven participants reported that they had no music training whereas the remaining 28 participants reported that they had between 1 and 30 years $(M=7.54$ years $)$ of formal music training.

Stimuli. Stimuli consisted of 21 excerpts from seven keyboard pieces each by Bach, Mozart, and Beethoven (see Appendix A). We selected the excerpts for each composer from 
412 plain MIDI transcriptions available on the Internet. All excerpts were of pieces written for piano

413 or harpsichord, and we avoided pieces we judged to be relatively familiar, such as those found in

414 elementary piano books, like Bach's short minuets, Mozart's Sonata in C, K. 545, or

415 Beethoven's Für Elise. We produced .wav files of CD quality from MIDI files, as follows: The

416 MIDI files had been transcribed directly into MIDI form from the musical scores, with no

417 attention to nuances of dynamics, phrasing, or variations in tempo (e.g., files found at

418 http://www.madore.org/ david/music/midi/). The excerpts were converted into .wav files using

419 Cakewalk Professional version 4.0 using an acoustic piano voice. Each excerpt lasted for 9 to 10

$420 \mathrm{~s}(M=9.67 \mathrm{~s})$. We linked the excerpts to audio icons arranged pseudorandomly on a PowerPoint

421 slide. Participants listened to the excerpts over good quality headphones.

422 Sorting tasks: Free and constrained. A sorting task is a simple but useful method to

423 examine implicit nonverbal processes, such as listeners' perception of stylistic aspects of the

424 melodies. Sorting tasks can reveal the underlying structure of a collection of items, in this case

425 musical excerpts. Similar to similarity-judgement and rating tasks, sorting tasks access implicitly

426 learned knowledge, in this case knowledge about stylistic aspects of melodies. However, sorting

427 tasks are considered to be more effective than judgement and rating tasks as they are less

428 strenuous on the participants, and can be used to compare experts and non-experts without

429 relying on either a specialized vocabulary or a quantitative response (Chollet, Valentin, \& Abdi,

430 2014). For instance, we conducted interviews with participants in the pilot study about their

431 experiences with the sorting task, and they all uniformly reported that the task was fun and not at

432 all tiring. Some researchers have indicated that untrained participants and especially children

433 have difficulty in verbalizing their perceptual responses to art forms (e.g., Gardner, 1973). Other

434 researchers have shown that participants' performance change in a verbal versus nonverbal 

447 activities.

musical task (e.g., Brown, 1981; Dibben, 2001). An added theoretical advantage for a nonverbal sorting task could be that participants are able to use their own concepts for categorizing stimuli especially in a free sort (e.g., Scott \& Canter, 1997), and are completely in control of the experiment in terms of its pace and time limit, so they probably find the task less taxing. As in Bigand, Vieillard, Madurell, Marozeau, and Dacquet (2005), Bigand, Filipic, and Lalitte (2005), and Scott and Canter (1997), the order of the two sorting tasks, free and constrained, could not be alternated as the purpose of the free sort was to have participants categorize the excerpts without specific direction, whereas the purpose of the constrained sort was to re-categorize the same excerpts based on specific instructions. Sorting tasks are commonly employed in studies on sensory perception, such as food preference and quality. As far as we know, only one study (i.e., Gingras et al., 2011) has employed this method to assess listeners' perception of musical style, though listeners regularly apply sorting methods in their everyday musical and nonmusical

Procedure. In our experiment, we adapted the methodology used in Bigand, Vieillard, et al. (2005), and Bigand, Filipic, and Lalitte, (2005). We instructed participants to listen to each excerpt by clicking on its icon, and then to sort the icons into clusters based on their perceived similarity to each other - in particular based on whether they might have been written by the same composer. While sorting, participants could play each excerpt in any order they wished and as many times as they wanted similar to the methodology used by Bigand et al. and Gingras et al. (2011), and especially as the stimuli were presented to them in a random order with each task. However, we did not register the number of times participants heard each stimulus nor the order in which the stimuli were heard. Participants completed two types of sorting tasks sequentially: free sorting and constrained sorting. In the free sorting task, participants sorted the 21 excerpts 
458 into as many clusters as they thought necessary, with the constraints that there should be at least 459 two clusters, and that each cluster should contain at least two excerpts. In the constrained sorting 460 task, participants were required to sort the excerpts into three clusters only as we had excerpts 461 from three composers; this gave them more direction and should have helped them in sorting.

462 The whole task took approximately 20 to 40 min to complete, depending on how often the 463 participant listened to the various excerpts.

Data Analysis. We recoded each participant's sorting data as a distance matrix. Excerpts

465 sorted together were assigned a distance of 0 , whereas excerpts sorted into different groups were 466 assigned a distance of 1 . To analyze the perceived differences among the excerpts, we then used 467 an updated version of DiSTATIS (Abdi, Williams, Valentin, \& Bennani-Dosse, 2012).

468 DiSTATIS is a generalization of two multivariate methods: metric multidimensional scaling 469 (MDS; Abdi, 2007b), a method for analyzing a single distance matrix, and STATIS, a method 470 for executing multi-table principal component analysis (PCA; Abdi et al., 2012; Abdi \& 471 Williams, 2010). DiSTATIS is commonly used to assess multiple distance matrices, such as data 472 from sorting tasks (Abdi, Valentin, Chollet, \& Chrea, 2007; Abdi, 2007a), wherein each 473 participant produces a distance matrix. Here our application of DiSTATIS relies on a priori 474 knowledge, namely the fact that we used excerpts from exactly three composers (and in 475 Experiment 2, four pianists).

477 (i.e., combined), and decomposed to give a factor map. To double-center the matrices (Abdi, 478 2007b), a distance matrix is converted to a covariance matrix centered on the origin. In this way, 479 double-centering brings disparate matrices to the same center (similar to centering as in 480 calculating $z$ scores). Double-centered matrices are normalized in the style of multiple factor 
481 analysis (Abdi, Williams, \& Valentin, 2013), where each double-centered matrix is divided by its

482 first eigenvalue so that the scales of the tables are comparable. These double-centered and

483 normalized tables are then subjected to an analysis of between-table similarity, called $R_{V}$ analysis

484 (Abdi, 2010), in order to identify typical and atypical tables. The $R_{V}$ analysis provides a set of

485 table weights, such that atypical tables receive small weights. The weighted average of these

486 tables gives the best possible single representation of all the tables, called the compromise table

487 (Abdi et al., 2012). Finally, the compromise table is decomposed by PCA to generate

488 components. Thus, DiSTATIS reveals the best possible single representation of the perceived

489 relationships among the stimuli.

490

The advantage of using DiSTATIS is that, unlike MDS and PCA, it retains the

491 information provided by the pattern of each participant's responses, but like MDS and PCA,

492 DiSTATIS produces new variables, called components (also called dimensions, factors, or

493 principal axes). Components are ordered by strength and are mutually orthogonal. That is, the

494 first component explains the maximum possible variance, and the subsequent components

495 explain the maximum remaining variance under the constraint that each subsequent component is

496 orthogonal to all prior components. The coordinates of the stimuli on the components are called

497 factor scores.

$498 \quad$ For ease of visualization, typically two components are plotted in what is called a

499 component map. On this map, observations are interpreted by their distances from each other and

500 their positions on the components. Observations near each other are similar. An observation that

501 has a large factor score on a given component contributes much variance to that component.

502 Each component may reflect an effect measured along that dimension, which may relate to a

503 perceived difference between the observations (e.g., staccato vs. legato). Thus, two observations 
504

505

506

507

508

509

510

511

512

513

514

515

516

517

518

519

520

521

522

523

524

525

526

on the same side of a component are perceived as similar on that dimension, whereas observations on opposite sides of a component are perceived as different on that dimension. In the figures, dots representing excerpts are color-coded by composer, and a square box in the appropriate color indicates each composer's average position.

We also performed inference tests in the form of nonparametric bootstrap resampling to test the stability of differences between groups. We tested the differences among the three groups of composers, and also among three levels of music training of the participants: 11 untrained participants, 10 moderately trained musicians ( 1 to 4 years of training, $M=2.60$ years), and 18 highly trained musicians ( 5 or more years of training, $M=10.28$ years). Previous studies have shown that people with 5 or more years of formal music training perform differently on musical tasks than those with less than 5 years of training or those with no training at all. For example, Dowling (1986), and Dowling and Bartlett (1981) showed strong differences in performance between people with average of 5 years of music lessons than those without any. Bootstrap resampling consists of resampling participants within groups with replacement (DiCiccio \& Efron, 1996), a procedure intended to simulate sampling from the population of individuals from which the participants are drawn. Bootstrap samples are collected repeatedly (here, 1,000 times) to generate successive distributions of the groups. For each group, the most extreme 5\% bootstrap-sampled means are removed, leaving a peeled convex hull that contains $95 \%$ of the bootstrap-sampled means, giving a $95 \%$ bootstrap confidence interval. For visualization, a smoothed ellipse is fitted around the convex hull, and so is slightly more conservative than the convex hull itself. We conducted the analyses in R (version 2.15.2; R Core Team, 2012), adapting the DistatisR (Beaton, Chin-Fatt, \& Abdi, 2014a; Beaton, Chin-Fatt, \& Abdi, 2014b) and the MExPosition (Chin-Fatt, Beaton, \& Abdi, 2013) packages to that use. 
527 Results

We conducted DiSTATIS analyses on the data from Experiments 1 and 2 separately for

529 the free and constrained sorting tasks. Table 1 shows the percent of variance explained by the

530 first four components in each of the four overall analyses in which the sorting was based on 531 composers. These components explain between 5.28 and $21.47 \%$ of the variance in the four 532 analyses.

\section{Free Sorting.}

Composers. Figure 1 shows that Components 1, 2, and 3 captured the effects of composer. Component 1 differentiated Beethoven from the other two composers. To a lesser extent Component 2 differentiated Mozart from the other two. Component 3 differentiated Bach

537 from Mozart and Beethoven, whereas for Component 4 there were no apparent differences due to 538 composer.

Music Training. Figure 2 shows the results of the $R_{V}$ analysis for sorting patterns

540 produced by the participants. Here, each dot corresponds to a participant. Participants were

541 color-coded according to level of music training: highly trained, moderately trained, and

542 untrained. Component 1 displayed a non-significant effect in which highly trained musicians

543 were separated from the others. Component 2 indicated a separation between moderately trained 544 musicians and untrained participants, but with highly trained musicians in between. Subsequent 545 components did not reveal between-group effects.

546 Constrained Sorting.

547 Composers. In Figure 3, Components 1, 2, and 4 showed that pieces by Beethoven were 548 clearly distinguished from those of the other composers. Component 3 differentiated Bach from 549 the other composers. 
Music Training. Figure 4 shows the results of the $R_{V}$ analysis. No effects of music training were found; and the three groups behaved more similarly with constrained sorting than they did with free sorting.

\section{Experiment 2: Natural stimuli}

\section{Method}

Participants. Thirty-seven participants, mean age 23.27 years (range $=17$ to 50 years), took part in Experiment 2. Ten participants reported that they had no music training whereas the remaining 27 participants reported that they had between 1 and 15 years $(M=4.89$ years $)$ of formal music training.

Stimuli. Stimuli consisted of 36 newly selected excerpts from commercial CD recordings: 12 pieces each by Bach, Mozart, and Beethoven. Each of four pianists-Arrau, Barenboim, Pirès, and Richter-played three different pieces by each composer (see Appendix B). This enabled us to assess the constancy of a composer's place in the sorting patterns across varied pianists, and the degree to which differences among the pianists affected sorting. As in Experiment 1, we avoided relatively familiar works. We were constrained by the selection of works that the particular pianists had recorded. For example, Richter had mainly recorded Bach's Wohltemperierte Klavier, whereas Arrau had mainly recorded partitas and suites. In contrast to Experiment 1, these excerpts exhibited all the nuances of phrasing and dynamics characteristic of musical performances. Each excerpt was at least $9 \mathrm{~s}$ in length, and ended at a musically coherent place, so that they varied in length from 9 to $15 \mathrm{~s}(M=11.64 \mathrm{~s})$. Presentation of stimuli was the same as in Experiment 1.

Procedure and Data Analysis. The procedure and data analysis were the same as those of Experiment 1 except for the following differences: The total duration of the task was 
573 approximately 30 to $45 \mathrm{~min}$, depending on the participant. And the groupings addressed by the

574

575

576

577

578

579

580

581

582

583

584

585

586

587

588

589

590

591

592

593

594

595

DiSTATIS nonparametric bootstrap resampling analyses included contrasts among the four

pianists as well as among composers. Categorization of participants' expertise was the same as in

Experiment 1, with 10 untrained participants, 17 moderately trained musicians $(M=2.06$ years $)$, and 10 highly trained musicians $(M=9.70$ years $)$.

\section{Results}

Free Sorting.

Composers. In Figure 5, Components 1 and 2 differentiated Mozart from Beethoven, with Bach's excerpts clustered near the origin. Component 3 differentiated Bach from Beethoven, and Component 4 differentiated Mozart from the other two.

Pianists. Figure 6 shows the results regarding pianists. Component 1 differentiated Richter from Pirès. Component 2 differentiated Richter and Pirès from Barenboim, with Arrau in the middle. Component 3 differentiated between Richter and Barenboim with Arrau and Pirès in the middle. Arrau was consistently positioned near the origin. Note that Figures 5a and 6a suggest a connection between composer and pianist, such that Barenboim appears to be definitely associated with Beethoven, with Pirès and Richter more associated with Mozart, and Arrau appears at the origin along with Bach.

Music Training. Figure 7 shows the results of the $R_{V}$ analysis. Component 1 indicated an effect of musical experience, significantly separating low and high levels of musical training with moderate levels in between. There were no other clear effects.

\section{Constrained Sorting.}

Composers. In Figure 8, Components 1, 2, and 4 distinguished between Beethoven and Mozart, whereas Component 3 differentiated Bach from the other two. 
Pianists. Figure 9 shows the results in terms of pianists. Richter and Barenboim were 603 effects. consistently perceived as distinct. Component 2 differentiated Pirès from Barenboim.

Components 3 and 4 taken together distinguished Barenboim and Arrau from Richter and Pirès. Note that Figures 8a and 9a show a relationship between composer and pianist, similar to that seen in Figures 5a and 6a.

Music Training. Figure 10 shows the results of the $R_{V}$ analysis. Component 1 displayed a non-significant difference indicating a weak effect of musical training. There were no other

In considering these results, let us first look at the contrast between free sorting and constrained sorting. In general, constrained sorting produced greater agreement among the 607 listeners than free sorting (which was done first), as shown by the amount of variance explained 608 by the successive factors in the DiSTATIS solutions (see Table 1). Especially in Experiment 2, 609 the gain attributable to constrained sorting is substantial. In both experiments, the total amount of 610 variance explained for constrained sorting by the first four factors is around $50 \%$, compared 611 with about $40 \%$ in Experiment 1 and about $30 \%$ in Experiment 2 for free sorting. Constraining

612 the sorting to just three categories forced listeners to make difficult choices of whether to put 613 excerpts in the same cluster, which they had perhaps avoided in the free sort by creating more 614 categories. And those choices led to greater consistency and agreement among the listeners in 615 their categorization of style. This increase in consistency was accompanied by greater 616 convergence among the groups of listeners with different amounts of musical training, as seen in

617 going from Figure 2 to Figure 4 for Experiment 1, and from Figure 7 to Figure 10 for

618 Experiment 2. These results suggest that in constrained sorting, the untrained and the moderately 
619 trained groups appear to be using much the same features for making decisions about

620

621

622

623

624

625

626

627

628

629

630

631

632

633

634

635

636

637

638

639

640

641

compositional style. And there is considerable overlap between the features they use and the

features used by the more highly trained groups. In general, in this regard these results agree with those of Dalla Bella and Peretz (2005), Eastlund (1992), Gingras et al. (2011), Gromko (1993), and Wedin (1969). These results also concur with those of Brown (1981) and Dibben (2001), in that untrained and trained listeners perform similarly in nonverbal music tasks. In regard to Miller's (1979) finding that untrained listeners tend to rely more on affective qualities of the excerpts, we note that the convergence across training levels was more emphatic in Experiment 2, where those affective qualities were more evident in the naturalistic excerpts, than in Experiment 1, where they were largely absent.

Since the constrained sorts were more coherent than the free sorts, in what follows we will concentrate on them. In Experiment 1, Figure 3a shows that the first component tends to separate the three composers according to their historical order: Bach, Mozart, and Beethoven. This is in agreement with the results of Dalla Bella and Peretz (2005) who suggested that this categorization was largely driven by the increase in rhythmic freedom as style developed from the baroque through the classical to the romantic. Such an increase in rhythmic freedom involves features that would be quite evident in the MIDI versions of Experiment 1, so this interpretation strikes us as entirely appropriate. The second component in Figure 3a appears to contrast Bach and Mozart with Beethoven. Among the readily available features in the MIDI excerpts, harmonic complexity suggests itself as underlying this contrast: Bach and Mozart are notably more complex in their harmonic progressions than Beethoven, especially the relatively early Beethoven represented in Experiment 1 (see Appendix A). (This local trend runs counter to the more general historical trend noted by Dalla Bella and Peretz of an increasingly freer use of the 
642 tonal system over the last three centuries.) The third component (Figure 3b) contrasts Mozart and

643 Beethoven with Bach, and may have to do with constancy of texture. As noted above, Bach's

644 writing typically involved the simultaneous presentation of two or three separate melodic lines in

645 a texture that remains generally constant throughout an excerpt, and this textural consistency is

646 obvious in these MIDI excerpts. Mozart and Beethoven, in contrast, shift their textures often,

647 between few versus many simultaneous notes, and between pitch regions, and those shifts are

648 also obvious in the MIDI transcriptions. Component 4 (Figure 3b) again contrasts Bach and

649 Mozart with Beethoven, but we do not venture an interpretation.

650

Turning to the naturalistic excerpts of Experiment 2, we see in Component 1 (Figure 8a)

651 an ordering of Beethoven-Bach-Mozart. With the live pianists we think this reflects differences

652 in the forcefulness of the performances, involving dynamic (loudness) contrasts. Beethoven uses

653 the greatest dynamic contrasts, and with these pianists Bach comes a close second, whereas

654 Mozart is more reserved and delicate. Component 2 (Figure 8a) appears to reflect large-scale

655 rhythmic unpredictability, in which the less predictable Beethoven is contrasted with the more

656 predictable Bach and Mozart. This contrast was accentuated in the live performances because the

657 pianists tended to give dynamic emphasis to Beethoven's rhythmic surprises, which led to a

658 different result here than in Experiment 1 (see Component 1 in Figure 3a) where no such

659 emphasis could occur. As a result, the three composers do not line up in historical order on what

660 we are thinking of as a dimension of rhythmic complexity as they did in Experiment 1 and in

661 Dalla Bella and Peretz (2005). Component 3 (Figure 8b) comes close to putting them in

662 historical order, though Mozart and Beethoven overlap to a considerable degree. We think this

663 dimension can be attributed to variability of texture, similar to Component 3 of Experiment 1

664 (Figure 3b). Bach's pieces tend to stick with the same relatively closed texture for long periods 
665 of time, in contrast to those of Mozart and Beethoven, who often shift the texture in density and 666 pitch range. We interpret Component 4 (Figure 8b) as concerned with emotional engagement.

667 Mozart (probably now more than in his own time) tends to be heard as elegant and above the

668 fray, whereas Bach, and to an even greater extent Beethoven, tend to be heard as passionate and 669 emotionally engaged. For Bach, this is especially true in performances by the pianists

670 represented here (especially Barenboim, Arrau, and Richter), in contrast to a number of pianists 671 who specialize in Bach, such as Glenn Gould and Rosalyn Tureck.

We now turn to the constrained sorts of Experiment 2 viewed in terms of the pianists

673 (Figures 9a \& 9b). Keep in mind that the solution that underlies these figures is the same as the

674 solution in Figure 8; that is, all the individual points pertaining to excerpts are the same, but now

675 the means ("barycenters") are calculated by grouping each pianist's points together, rather than

676 each composer's. So, Component 1 (Figure 9a) appears to indicate affinities between the pianists

677 and particular composers: Barenboim with Beethoven, Arrau and Pirès with Bach, and Richter

678 with Mozart. This last pairing is somewhat of a surprise, as in his career Richter was more

679 typically associated with Beethoven and Bach than with Mozart. On the other hand, as Villemin 680 (1999) noted, Richter was known for adapting his style to that of the composer he was playing,

681 and so among the pianists here he may have been the best fit for Mozart. His Mozart in these

682 excerpts was certainly among the most expressive performances of them. Component 2 (Figure

683 9a) may concern overall heaviness of the texture, ranging from the relatively dark and heavy

684 piano sound of the early Barenboim, to a moderately heavy sound of Arrau and Richter, to the 685 very light sound of Pirès. This order parallels the progression from Bach through Beethoven to 686 Mozart in Component 2 for composers (Figure 8a). Component 3 (Figure 9b) represents clarity 687 of texture: Barenboim and Arrau (denser) versus Richter and Pirès (clear and lucid). (Component 
3 for composers (Figure 8b) contrasted the relatively dense Bach with the more open Mozart and Beethoven.) And we do not venture to interpret Component 4 (Figure 9b).

One of the primary goals of this study was to verify the effectiveness of a sorting task and its analysis using DiSTATIS in musical style perception. The results showed that the sorting task could be successfully used to ascertain listeners' implicit knowledge of stylistic aspects, especially for untrained listeners. Many participants reported that they "had fun" sorting the excerpts, and that this task seemed less strenuous on them. Both music experts and non-experts performed similarly especially since the task did not rely on using technical vocabulary or any form of verbalization or quantification. On the other hand, knowing the basis of categorization of the melodies might help researchers understand the exact nature of cues (i.e., high-level or lowlevel) that each participant uses, and also to ascertain whether music training would influence the type of cues that listeners perceive. In a future study, researchers could ask participants to label each group of melodies after they complete both the free and constrained sorting tasks. Another reason for the untrained participants' competent performance on this task could be the use of excerpts from actual artistic performances, which contain a repository of cues pertaining to dynamics, texture, and so forth, not present in the MIDI versions of Experiment 1. Our study clearly showed that years of mere passive listening could facilitate the perception of such cues. One limitation of this study was that we did not assess the familiarity of our participants with each stimulus, and thus, we cannot estimate whether veridical knowledge (i.e., piece-specific information) helped the trained listeners in doing the task. Nevertheless, we did use relatively unfamiliar excerpts (see Appendices A and B), and, most importantly, we did not see much differences in the relative performance of the untrained and the two trained groups. Also, all participants performed the free sort first followed by the constrained sort, as by definition it is 
711 impossible to counterbalance the order of presentation (see also Bigand, Vieillard, et al., 2005;

712 Bigand, Filipic, \& Lalitte, 2005; Scott \& Canter, 1997, using the same order). This meant that all

713 participants doing the constrained sort were more familiar with the excerpts than in the free sort,

714 thus potentially contributing to more coherent and converging responses in the second task.

715 However, there is no confound here since all participants did the two tasks in the same sequence.

716 Moreover, we re-randomized the order of the excerpts in the second task, so that participants had

717 to re-categorize the excerpts based on the "new" constraints provided by the experimenter. A

718 second limitation of the study is that we did not track the number of times participants heard

719 each excerpt. For instance, Gingras et al. (2011), using the same sorting paradigm, found that the

720 total number of times participants listened to each excerpt correlated significantly with their

721 categorization accuracy. Also, an influence of musical expertise on problem-solving behavior in

722 a musical puzzle task was reported by Tillmann, Bigand, and Madurell (1998); in particular,

723 trained participants listened more often to the musical puzzle parts, but less often to the entire

724 musical piece than did untrained participants. These overall findings convergently show that

725 music experts tended to listen to the stimuli (or the parts of the puzzle individually) more often

726 than the novices, which probably enhanced the experts' performance in the task. Building on

727 these findings and our study, a future sorting experiment could investigate such a relationship

728 between musical expertise and problem solving or perceptual strategies further. Future studies

729 could also address if this task would be successful in discerning subtler and more nuanced

730 aspects of musical style. For instance, would trained and untrained participants be able to sort

731 melodies based on early versus late Beethoven's compositional style? Finally, an important

732 follow-up experiment would be to investigate the effectiveness of this task when applied in a

733 cross-cultural musical style perception study with expertise and familiarity as factors. 
734

735

736

737

738

739

740

741

742

743

744

745

746

747

748

749

750

751

752

753

754

\section{References}

Abdi, H. (2007a). Distance. In N. J. Salkind (Ed.), Encyclopedia of measurement and statistics (pp. 280-284). Thousand Oaks, CA: Sage. doi: 10.4135/9781412952644.n142

Abdi, H. (2007b). Metric multidimensional scaling (MDS): Analyzing distance matrices. In N. J. Salkind (Ed.), Encyclopedia of measurement and statistics (pp. 598-605). Thousand Oaks, CA: Sage. doi: 10.4135/9781412952644.n279

Abdi, H. (2010). Congruence: Congruence coefficient, $R_{V}$ coefficient, and Mantel coefficient. In N. J. Salkind (Ed.), Encyclopedia of research design (pp. 222-229). Thousand Oaks, CA: Sage. doi: 10.4135/9781412961288.n71

Abdi, H., Valentin, D., Chollet, S., \& Chrea, C. (2007). Analyzing assessors and products in sorting tasks: DiSTATIS, theory and applications. Food Quality \& Preference, 18(4), 627-640. doi:10.1016/j.foodqual.2006.09.003

Abdi, H., \& Williams, L. J. (2010). Principal component analysis. Wiley Interdisciplinary Reviews: Computational Statistics, 2(4), 433-459. doi:10.1002/wics.101

Abdi, H., Williams, L. J., \& Valentin, D. (2013). Multiple factor analysis: Principal component analysis for multi-table and multi-block data sets. Wiley Interdisciplinary Reviews: Computational Statistics, 5(2), 149-179. doi:10.1002/wics.1246

Abdi, H., Williams, L. J., Valentin, D., \& Bennani-Dosse, M. (2012). STATIS and DiSTATIS: Optimum multitable principal component analysis and three way metric multidimensional scaling. Wiley Interdisciplinary Reviews: Computational Statistics, 4(2), 124-167. doi:10.1002/wics.198 
Agres, K., Abdallah, S., \& Pearce, M. (2018). Information-theoretic properties of auditory sequences dynamically influence expectation and memory. Cognitive Science, 42, 43-76. doi: $10.1111 / \operatorname{cogs} .12477$

Atalay, B. V., \& Placek, R. (1997). Machine versus human: Responding to the task of identifying eras for selected keyboard pieces. In A. Gabrielsson (Ed.), Proceedings of the Third Triennial ESCOM Conference (pp. 521-526). Uppsala, Sweden: Uppsala University.

Beaton, D., Chin-Fatt, C. R., \& Abdi, H. (2014a). An ExPosition of multivariate analysis with the singular value decomposition in R. Computational Statistics \& Data Analysis, 72, 176-189. doi:10.1016/j.csda.2013.11.006

Beaton, D., Chin-Fatt, C. R., \& Abdi, H. (2014b). Package “ DistatisR .”

Bigand, E., Filipic, S., \& Lalitte, P. (2005). The time course of emotional responses to music. Annals of the New York Academy of Sciences, 1060(1), 429-437. doi: 10.1196/annals.1360.036

Bigand, E., \& Poulin-Charronnat, B. (2006). Are we "experienced listeners"? A review of the musical capacities that do not depend on formal musical training. Cognition, 100(1), 100130. doi:10.1016/j.cognition.2005.11.007

Bigand, E., Vieillard, S., Madurell, F., Marozeau, J., \& Dacquet, A. (2005). Multidimensional scaling of emotional responses to music: The effect of musical expertise and of the duration of the excerpts. Cognition \& Emotion, 19(8), 1113-1139. doi: $10.1080 / 02699930500204250$

Brown, R. (1981). Music and language. In Documentary report of the Ann Arbor Symposium: National symposium on the applications of psychology to the teaching and learning of music. Reston, VA: Music Educators National Conference. 
778 Chin-Fatt, C. R., Beaton, D., \& Abdi, H. (2013). Package "MExPosition."

779 Chollet, S., Valentin, D., \& Abdi, H. (2014). Free sorting task. In P.V. Tomasco \& G. Ares (Eds.), Novel techniques in sensory characterization and consumer profiling (pp. 207227). Boca Raton, FL: Taylor \& Francis.

782 783 784 785 786 787 788

789 790 791 792 793 794 795 796 797 798 799

Cope, D. (1991). Computers and musical style. Madison, WI: A-R Editions.

Crump, M. (2002). A principal components approach to the perception of musical style (Unpublished honors thesis). University of Lethbridge, Canada.

Dalla Bella S., \& Peretz, I. (2005). Differentiation of classical music requires little learning but rhythm. Cognition, 96, B65-B78. doi: 10.1016/j.cognition.2004.12.005

DiCiccio, T. J., \& Efron, B. (1996). Bootstrap confidence intervals. Statistical Science, 11(3), 189-212. Retrieved from https://www.jstor.org/stable/2246110

Dibben, N. (2001). What do we hear, when we hear music?: Music perception and music material. Musicae Scientiae, 5(2), 161-194. doi: 10.1177/102986490100500203

Dowling, W. J. (1986). Context effects on melody recognition: Scale-step versus interval representations. Music Perception, 3(3), 281-296. doi:10.2307/40285338

Dowling, W. J., \& Bartlett, J. C. (1981). The importance of interval information in long-term memory for melodies. Psychomusicology, 1(1), 30-49. doi: 10.1037/h0094275

Eastlund, J. O. (1992). A multidimensional scaling analysis of musical style. Journal of Research in Music Education, 40(3), 204-215. doi: 10.2307/3345682

Eerola, T., Järvinen, T., Louhivuori, J., \& Toiviainen, P. (2001). Statistical features and perceived similarity of folk melodies. Music Perception, 18(3), 275-296. doi: 10.1525/mp.2001.18.3.275 
800 801

802

803

804

805

806

807

808

809

810

811

812

813

814

815

816

817

818

819

820

821

822

Gardner, H. (1973). Children's sensitivity to musical styles. Merrill-Palmer Quarterly of Behavior and Development, 19(1), 67-77. Retrieved from https://www.jstor.org/stable/23083794

Gingras, B., Lagrandeur-Ponce, T., Giordano, B. L., \& McAdams, S. (2011). Perceiving musical individuality: Performer identification is dependent on performer expertise and expressiveness, but not on listener expertise. Perception, 40, 1206-1220. doi:

\section{$10.1068 / \mathrm{p} 6891$}

Gromko, J. E. (1993). Perceptual differences between expert and novice music listeners: A multidimensional scaling analysis. Psychology of Music, 21(1), 34-47. doi: $10.1177 / 030573569302100103$

Grout, D. J., \& Palisca, C. V. (1980). A history of western music (3 $3^{\text {rd }}$ ed.). New York, NY: W. W. Norton \& Company, Inc.

Gundlach, R. H. (1932). A quantitative analysis of Indian music. The American Journal of Psychology, 44(1), 133-145. doi: 10.2307/1414960

Hargreaves, D. J., \& North, A. C. (1999). Developing concepts of musical style. Musicae Scientiae, 3(2), 193-216. doi: 10.1177/102986499900300203

Hevner, K. (1936). Experimental studies of the elements of expression in music. The American Journal of Psychology, 48(2), 246-268. doi: 10.2307/1415746

Järvinen, T., Toiviainen, P., \& Louhivuori, J. (1999). Classification and categorization of musical styles with statistical analysis and self-organizing maps. In A. Patrizio, G. A. Wiggins, \& H. Pain (Eds.), Proceedings of the AISB'99 Symposium on Musical Creativity (pp. 54-57). Edinburgh, Scotland: The Society for the Study of Artificial Intelligence and Simulation of Behavior. 
823 Krumhansl, C. L. (2015). Statistics, structure, and style in music. Music Perception, 33(1), 20-

824

825

826

827

828

829

830

831

832

833

834

835

836

837

838

839

840

841

842

843

844

31. doi: 10.1525/mp.2015.33.1.20

Krampe, R. Th., \& Ericsson, K. A. (1996). Maintaining excellence: Deliberate practice and elite performance in young and older pianists. Journal of Experimental Psychology: General, 125, 331-359. doi:10.1037/0096-3445.125.4.331

Meyer, L. B. (1973). Explaining music: Essays and explorations. Berkeley, CA: University of California Press.

Meyer, L. B. (1989). Style and music: Theory, history, and ideology. Philadelphia, PA: University of Pennsylvania Press.

Miller, R. F. (1979). An analysis of musical perception through multidimensional scaling (Doctoral dissertation). Retrieved from ProQuest dissertations \& theses global. (Order No. 8004230)

Morrison, S. J., \& Yeh, C. S. (1999). Preference responses and use of written descriptors among music and nonmusic majors in the United States, Hong Kong, and the People's Republic of China. Journal of Research in Music Education, 47(1), 5-17. doi: 10.2307/3345824

Pascall, R. J. (1980). Style. In S. Stanley (Ed.), The new grove dictionary of music and musicians (pp. 316-321). London, UK: Macmillan.

R Core Team (2012). R: A language and environment for statistical computing. Vienna, Austria: R Foundation for Statistical Computing.

Raman, R., \& Dowling, W. J. (2016). Real-time probing of modulations in South Indian classical (Carnātic) music by Indian and Western musicians. Music Perception, 33(3), 367-393. doi: $10.1525 / \mathrm{mp} .2016 .33 .03 .367$ 
845 Raman, R., \& Dowling, W. J. (2017). Perception of modulations in South Indian classical

846

847

848

849

850

851

852

853

854

855

856

857

858

859

860

861

862

863

864

865

(Carnātic) music by student and teacher musicians: A cross-cultural study. Music

Perception, 34(4), 424-437. doi: 10.1525/mp.2017.34.4.424

Scott, M. J., \& Canter, D. V. (1997). Picture or place? A multiple sorting study of landscape. Journal of Environmental Psychology, 17(4), 263-281. doi: 10.1006/jevp.1997.0068

Smaill, A., \& Westhead, M. D. (1993). Automatic characterization of musical style. In M. Smith, A. Smaill, \& G. A. Wiggins (Eds.), Music education: An artificial intelligence approach (pp. 157-170). Berlin, Germany: Springer-Verlag.

Storino, M., Dalmonte, R., \& Baroni, M. (2007). An investigation on the perception of musical style. Music Perception, 24(5), 417-432. doi: 10.1525/mp.2007.24.5.417

Tekman, H. G., \& Hortaçsu, N. (2002). Aspects of stylistic knowledge: What are different styles like and why do we listen to them? Psychology of Music, 30, 28-47. doi: $10.1177 / 0305735602301005$

Tillmann, B., Abdi, H., \& Dowling, W. J. (2004). Musical style perception by a linear autoassociator model and human listeners. In S. D. Lipscomb, R. Ashley, R. O. Gjerdingen, \& P. Webster (Eds.), Proceedings of the 8th International Conference on Music Perception \& Cognition (ICMPC) (pp. 189-191). Adelaide, Australia: Causal Productions.

Tillmann, B., Bigand, E., \& Madurell, F. (1998). Local versus global processing of harmonic cadences in the solution of musical puzzles, Psychological Research, 61(3), 157-174. doi: $10.1007 / \mathrm{s} 004260050022$ 
866 Thorisson, T. (1998). Comparison of novice listeners' similarity judgements and style

867

868

869

870

871

872

873

874

875

876

877

878

879

880

881

882

883

884

885

886

887

888

83

84

85 categorisation of classic and romantic piano examplars. Psychology of Music, 26(2), 186196. doi: $10.1177 / 0305735698262006$

Tyler, L. E. (1946). An exploratory study of discrimination of composer style. The Journal of General Psychology, 34(2), 153-163. doi: 10.1080/00221309.1946.10544531

Vignal, M. (1987). Le dictionnaire de la musique. Paris, France: Larousse.

Villemin, S. (1999). Les grands pianistes. Geneva, Switzerland: Georg.

Watt, R. J., \& Ash, R. L. (1998). A psychological investigation of meaning in music. Musicae Scientiae, 2(1), 33-53. doi: 10.1177/102986499800200103

Wedin, L. (1969). Dimension analysis of the perception of musical style. Scandinavian Journal of Psychology, 10(1), 97-108. doi: 10.1111/j.1467-9450.1969.tb00015.x

Zivic, P. H. R., Shifres, F., \& Cecci, G. A. (2013). Perceptual basis of evolving Western musical styles. Proceedings of the National Academy of Sciences, 110(24), 10034-10038.

Retrieved from http://www.jstor.org/stable/42706125 
Appendix A

\begin{tabular}{|c|c|c|c|}
\hline No. & Composer & Key & Title \\
\hline 1 & Bach & A & English Suite No. 1, Guigue 806 \\
\hline 2 & & $\mathrm{~B}^{\mathrm{b}}$ & Partitas No. 1, BWV 825 \\
\hline 3 & & $\mathrm{C}$ & Three-Part Invention, BWV 787 \\
\hline 4 & & C-minor & French Suite No. 2, BWV 813 \\
\hline 5 & & $\mathrm{D}$ & Prelude No. 5, BWV 850 (Well-tempered Piano I) \\
\hline 6 & & $\mathrm{~F}$ & Little Fugue, BWV 556 \\
\hline 7 & & $\mathrm{G}$ & French Suite No. 5, BWV 816 \\
\hline 8 & Mozart & A & Sonata K331, Allegro \\
\hline 9 & & $\mathrm{~B}^{\mathrm{b}}$ & Sonata K281, Allegro \\
\hline 10 & & $\mathrm{C}$ & Sonata K545, Allegro \\
\hline 11 & & C-minor & Sonata K457, Allegro assai \\
\hline 12 & & $\mathrm{D}$ & Sonata K576, Allegro \\
\hline 13 & & $\mathrm{~F}$ & Sonata K280, Allegro \\
\hline 14 & & $\mathrm{G}$ & Sonata K283, Allegro \\
\hline 15 & Beethoven & A & Sonata No. 2, Op. 2, Allegro \\
\hline 16 & & $\mathrm{~B}^{\mathrm{b}}$ & Sonata No. 11, Op. 22 \\
\hline 17 & & $\mathrm{C}$ & Sonata in C, Op. 21, Allegro con brio \\
\hline 18 & & C-minor & Sonata No. 5, Op. 10 No. 1, Allegro \\
\hline 19 & & $\mathrm{D}$ & Sonata No. 7, Op. 10, Presto \\
\hline
\end{tabular}


F $\quad$ Sonata No. 6, Op. 10 No. 2 
Appendix B

Experiment 2: Natural Stimuli

\begin{tabular}{|c|c|c|c|c|}
\hline No. & Composer & Pianist & Key & Title \\
\hline \multirow[t]{2}{*}{1} & Bach & Arrau & & Partita No. 2: Rondeaux \\
\hline & & & & Philips 434 904-2 \\
\hline \multirow[t]{2}{*}{2} & & & & Partita No. 3: Fantasia \\
\hline & & & & Philips 434 904-2 \\
\hline \multirow[t]{2}{*}{3} & & & & Partita No. 5: Praeambulum \\
\hline & & & & Philips 434 904-2 \\
\hline \multirow[t]{2}{*}{4} & & Barenboim & & Goldberg Variations: Var. 18 \\
\hline & & & & Erato $741397 \mathrm{~T}$ \\
\hline \multirow[t]{2}{*}{5} & & & & Goldberg Variations: Var. 5 \\
\hline & & & & Erato $741397 \mathrm{~T}$ \\
\hline \multirow[t]{2}{*}{6} & & & & Goldberg Variations: Var. 6 \\
\hline & & & & Erato 741397 \\
\hline \multirow[t]{2}{*}{7} & & Pirès & & Partita No. 1: Praeludium \\
\hline & & & & Philips 456 928-2 \\
\hline \multirow[t]{2}{*}{8} & & & & English Suite No. 3: Prelude \\
\hline & & & & Philips 456 928-2 \\
\hline \multirow[t]{2}{*}{9} & & & & French Suite No. 2: Allemande \\
\hline & & & & Philips 456 928-2 \\
\hline \multirow[t]{2}{*}{10} & & Richter & & Das Wohltemperierte Clavier, Book I: Prelude 2 \\
\hline & & & & RCA Victor GD 60949 \\
\hline
\end{tabular}


11

12

13 Mozart Arrau

14

15

16

17

18

19

20

21

22

Pirès
Das wohltemperierte Clavier, Book I: Prelude 5

RCA Victor GD 60949

Das wohltemperierte Clavier, Book II: Prelude 6

RCA Victor GD 60949

Sonata, KV 284: mvmt 1

Philips 432 306-2

Sonata, KV 330: mvmt 1

Philips 432 306-2

Sonata, KV 576: mvmt 1

Philips 432 306-2

Barenboim Sonata, KV 281: mvmt 1

EMI CDZE 7672942

Sonata, KV 533: mvmt 1

EMI CDZE 7672942

Sonata, KV 311: mvmt 1

EMI CDZE 7672942

Sonata, KV 280: mvmt 1

DG 435 882-2

Sonata, KV 282: mvmt 3

DG 435 882-2

Sonata, KV 333: mvmt 1

DG 435 882-2

Richter Sonata, KV 283: mvmt 1 
Philips 438 480-2

23

Sonata, KV 310: mvmt 1

Philips 422 583-2

24

Sonata, KV 457: mvmt 1

Philips 438 480-2

25 Beethoven Arrau

Sonata No. 15, op. 28: mvmt 1

Philips 426 068-2

26

Sonata No. 21, op. 53: mvmt 1

Philips 426 068-2

Sonata No. 26, op. 81a: mvmt 3

Philips 426 068-2

Sonata No. 22, op. 54: mvmt 2

EMI 5729122

Sonata No. 11, op. 22: mvmt 1

EMI 5729122

Sonata No. 28, op. 101: mvmt 2

EMI 5729122

Sonata No. 14, op. 27, no. 2: mvmt 3

Erato 3984274872

Erato 3984274872 
$34 \quad$ Richter

35

36
Sonata No. 7, op. 10, no. 3: mvmt 1

Praga 354022

Sonata No. 3, op. 2, no. 3: mvmt 1

Brilliant 92229/3

Sonata No. 31, op. 110: mvmt 2

Philips 454 949-2

914

915

916

917

918

919

920

921

922

923

924

925

926

927

928

929

930 
931 Table 1.

932 Variance (\%) explained by the first four components in Experiments 1 and 2 in terms of 933 composers.

934

\begin{tabular}{|c|c|c|c|c|}
\hline & \multicolumn{2}{|c|}{ Experiment 1} & \multicolumn{2}{|c|}{ Experiment 2} \\
\hline & Free & Constrained & Free & Constrained \\
\hline Component-1 & 13.83 & 19.70 & 10.58 & 21.47 \\
\hline Component-2 & 11.03 & 13.21 & 7.93 & 13.03 \\
\hline Component-3 & 8.06 & 9.44 & 5.89 & 7.03 \\
\hline Component-4 & 6.82 & 7.83 & 5.28 & 5.76 \\
\hline
\end{tabular}

935

936

937

938

939

940

941

942

943

944 
946 Figure 1. Compromise factor scores for Experiment 1: Free sorting task with MIDI stimuli,

947 color-coded by composers (Bach: purple; Mozart: green; Beethoven: lavender). Panel (a)

948 Components 1 and 2, and Panel (b) Components 3 and 4.

949 Figure 2. $R_{V}$ factor scores for Experiment 1: Free sorting task with MIDI stimuli, color-coded by 950 musical experience (highly trained: orange; moderately trained: red; untrained: blue). Each dot 951 represents a participant and the numbers corresponding to each dot represent the years of music 952 training.

953 Figure 3. Compromise factor scores for Experiment 1: Constrained sorting task with MIDI

954 stimuli, color-coded by composers (Bach: purple; Mozart: green; Beethoven: lavender). Panel (a)

955 Components 1 and 2, and Panel (b) Components 3 and 4.

956 Figure 4. $R_{V}$ factor scores for Experiment 1: Constrained sorting task with MIDI stimuli, color-

957 coded by musical experience (highly trained: orange; moderately trained: red; untrained: blue).

958 Each dot represents a participant and the numbers corresponding to each dot represent the years 959 of music training.

960 Figure 5. Compromise factor scores for Experiment 2: Free sorting task with natural stimuli, 961 color-coded by composers (Bach: purple; Mozart: green; Beethoven: lavender). Panel (a)

962 Components 1 and 2, and Panel (b) Components 3 and 4.

963 Figure 6. Compromise factor scores for Experiment 2: Free sorting task with natural stimuli, 964 color-coded by pianists (Arrau: purple; Barenboim: orange; Pirès: pink; Richter: red). Panel (a) 965 Components 1 and 2, and Panel (b) Components 3 and 4.

966 Figure 7. $R_{V}$ factor scores for Experiment 2: Free sorting task with natural stimuli, color-coded 967 by musical experience (highly trained: orange; moderately trained: red; untrained: blue). Each 
968 dot represents a participant and the numbers corresponding to each dot represent the years of 969 music training.

970 Figure 8. Compromise factor scores for Experiment 2: Constrained sorting task with natural

971 stimuli, color-coded by composers (Bach: purple; Mozart: green; Beethoven: lavender). Panel (a)

972 Components 1 and 2, and Panel (b) Components 3 and 4.

973 Figure 9. Compromise factor scores for Experiment 2: Constrained sorting task with natural 974 stimuli, color-coded by pianists (Arrau: purple; Barenboim: orange; Pirès: pink; Richter: red).

975 Panel (a) Components 1 and 2, and Panel (b) Components 3 and 4.

976 Figure 10. $R_{V}$ factor scores for Experiment 2: Constrained sorting task with natural stimuli,

977 color-coded by musical experience (highly trained: orange; moderately trained: red; untrained:

978 blue). Each dot represents a participant and the numbers corresponding to each dot represent the 979 years of music training.

980

981

982

983

984

985

986

987

988

989

990 
991

992

993

994

995

996

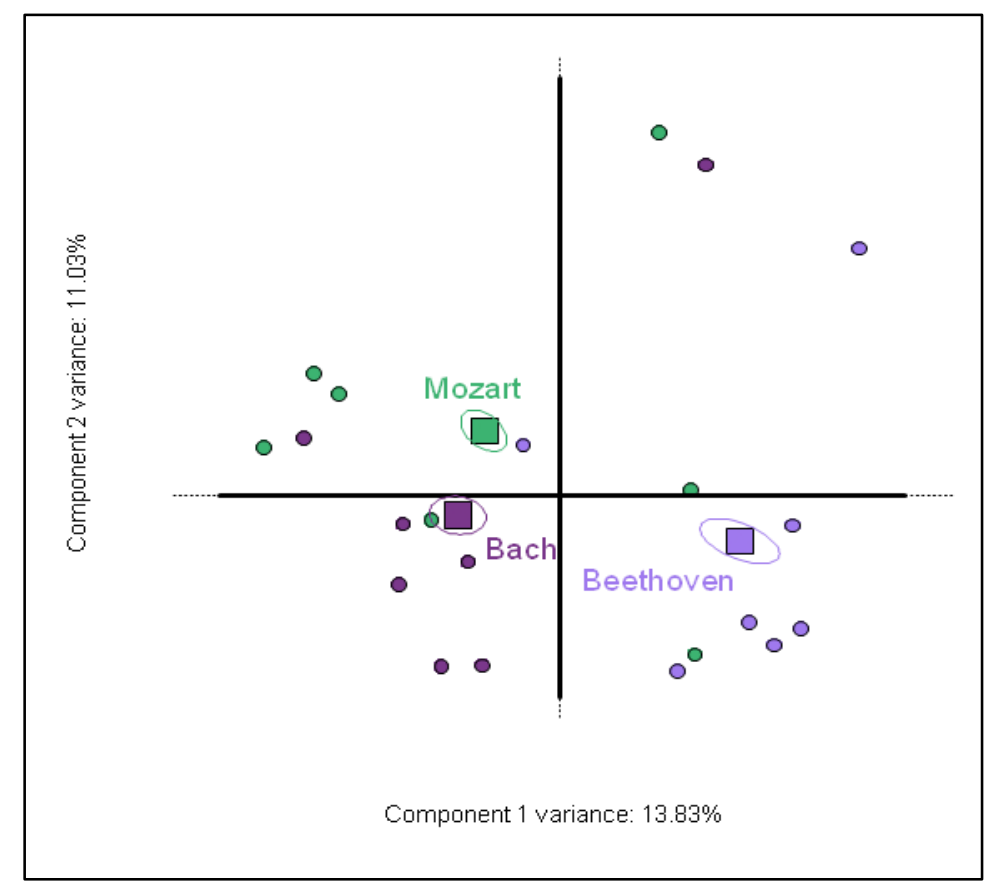

(a)

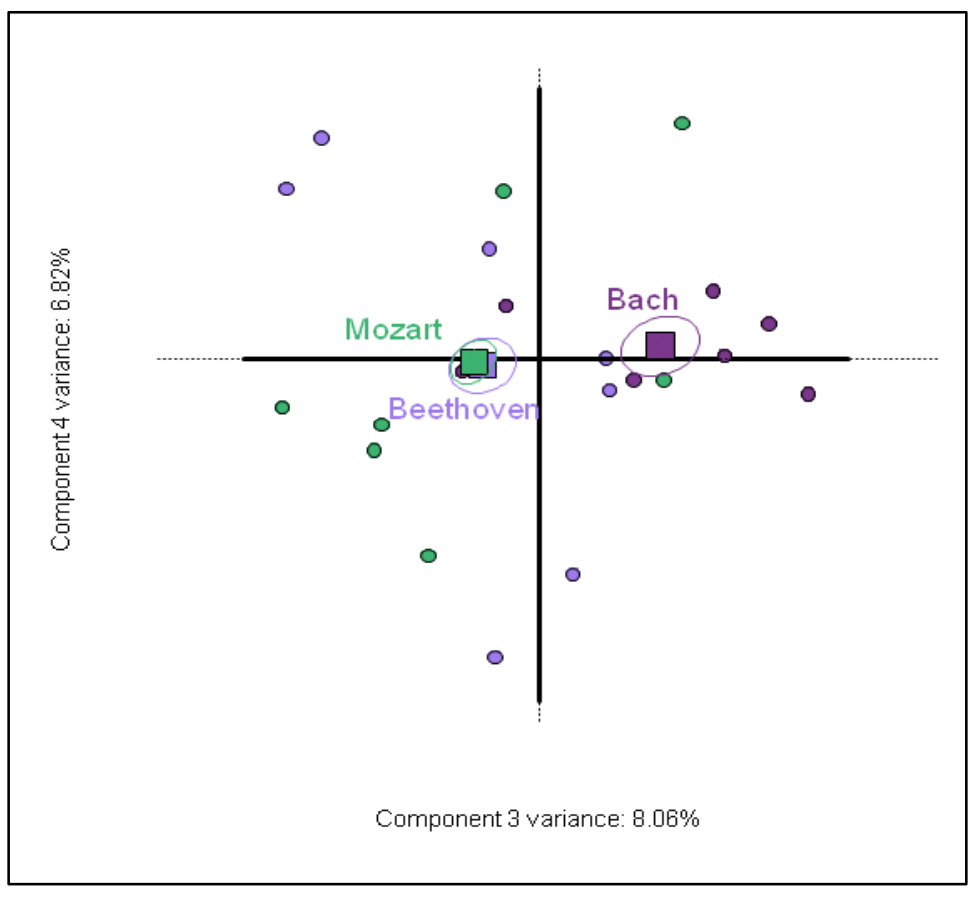

(b)

Figure 1. 


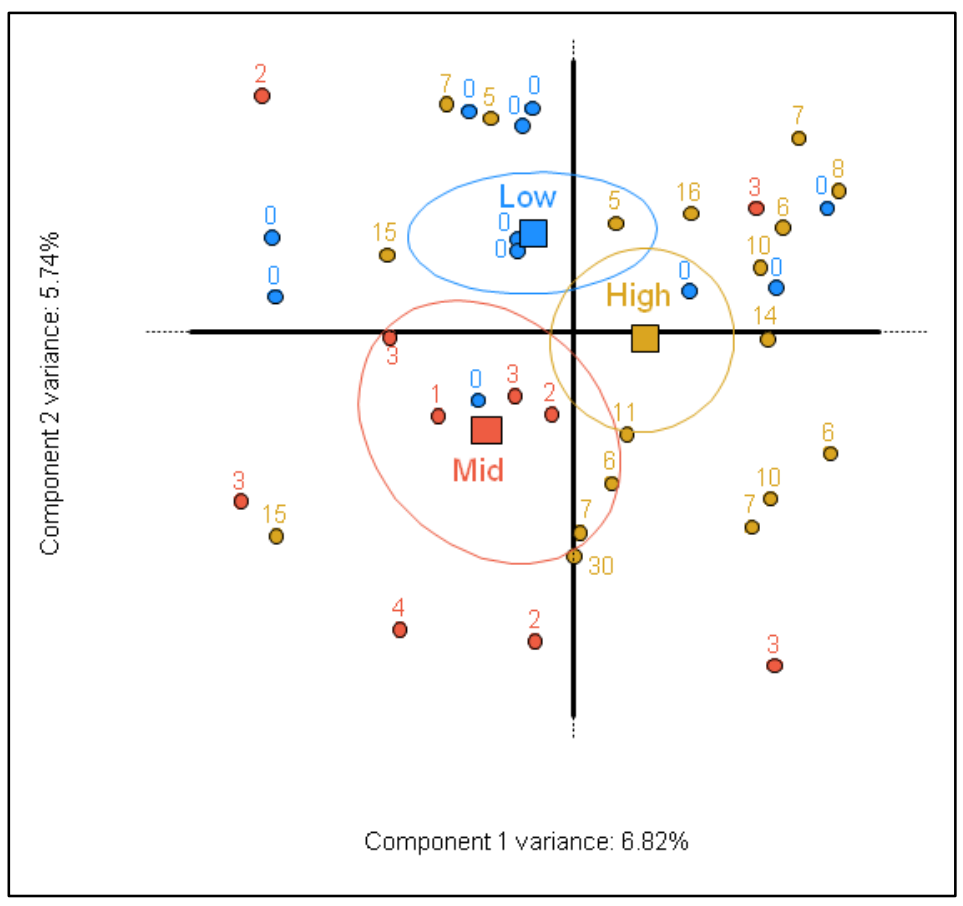

998

999

Figure 2.

1000

1001

1002

1003

1004

1005 


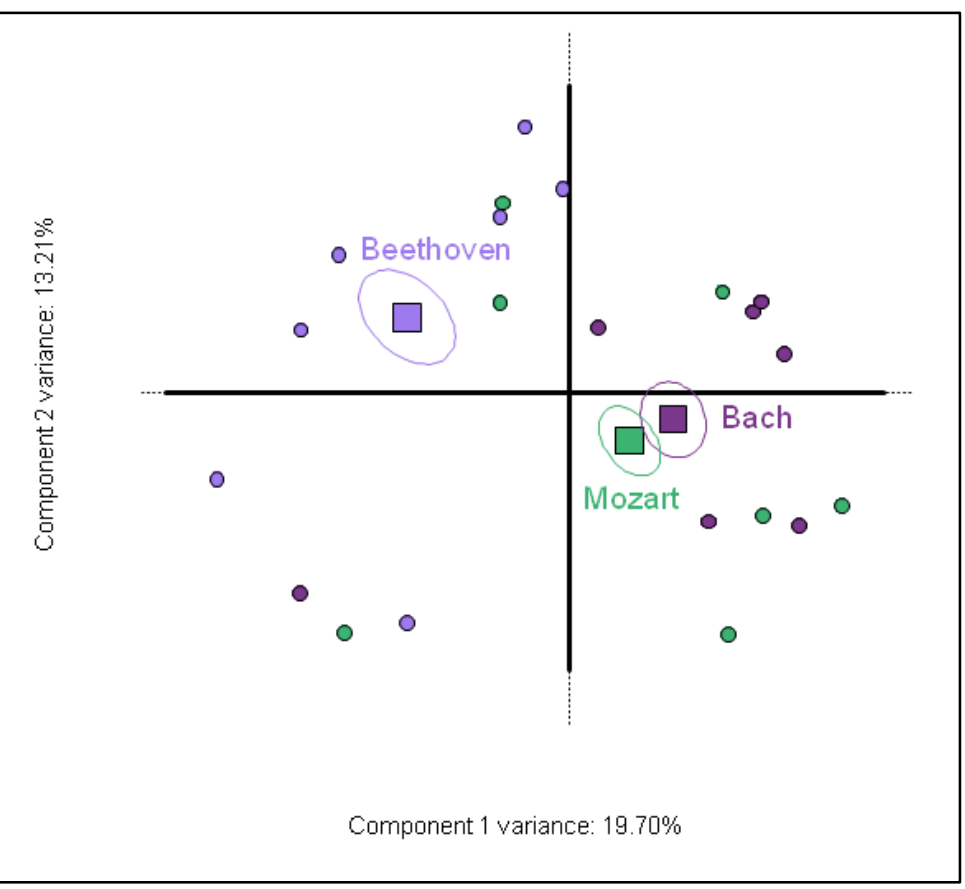

1007

(a)

1008

Component 3 variance: $9.44 \%$

(b)

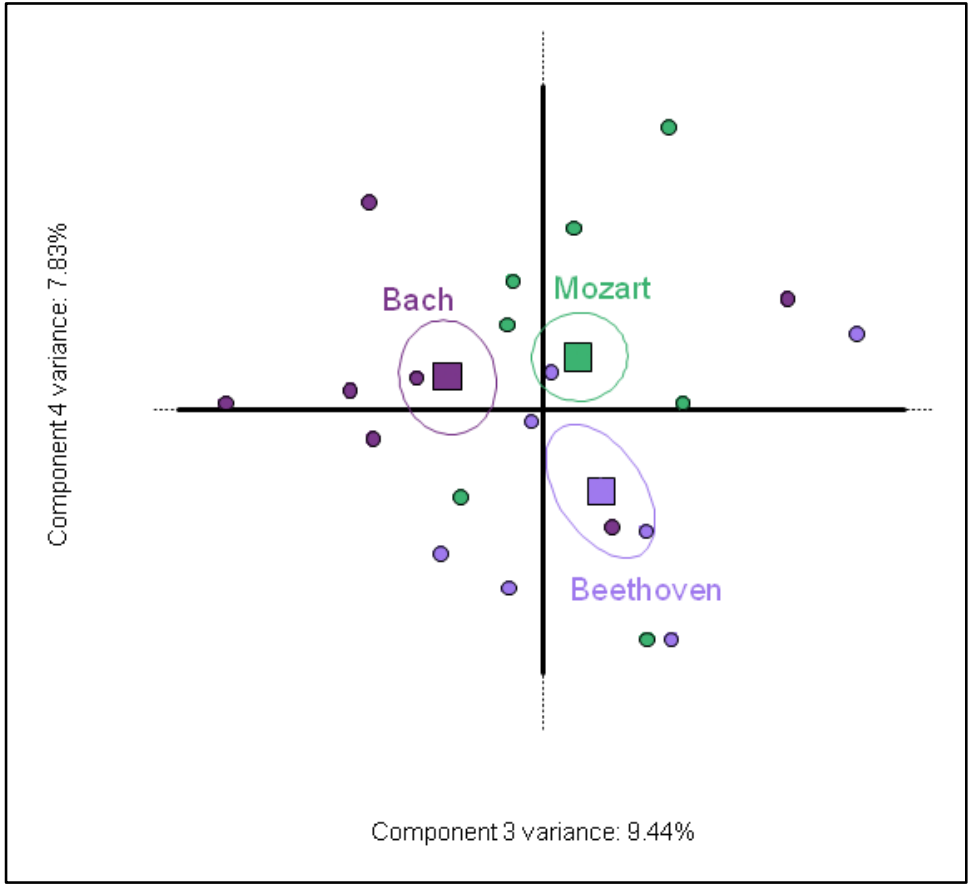

Figure 3. 


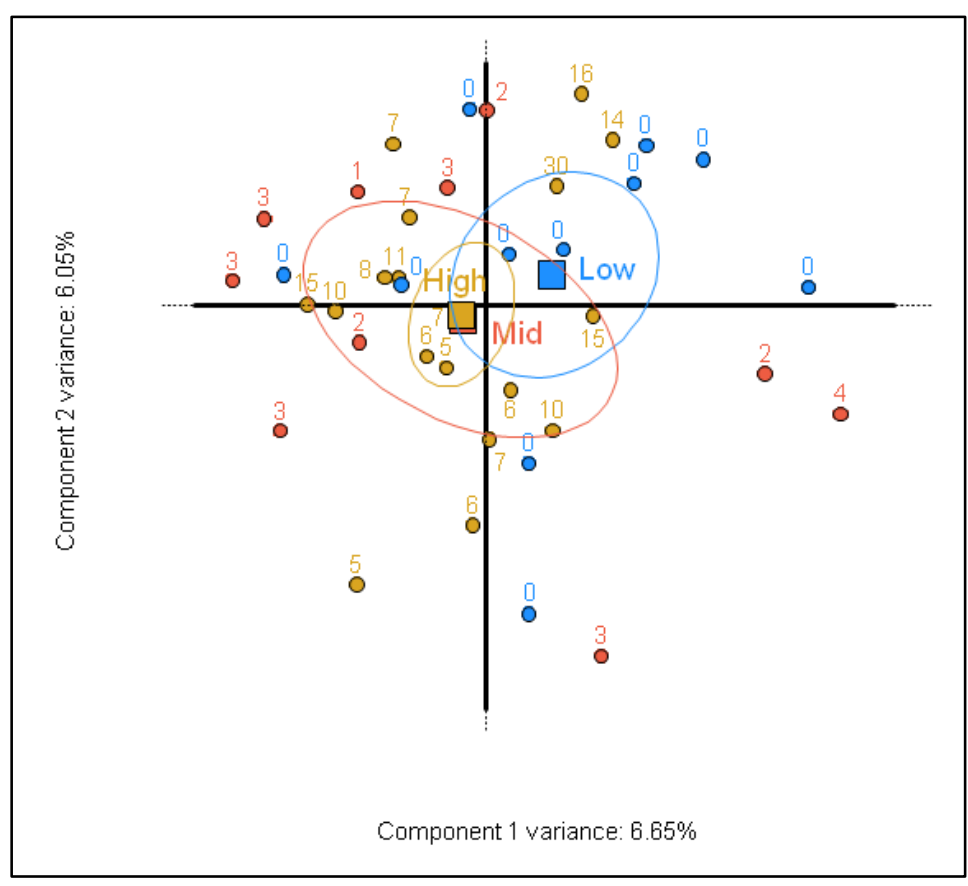

1013

1014

Figure 4.

1015

1016

1017

1018

1019

1020

1021

1022

1023

1024

1025

1026 


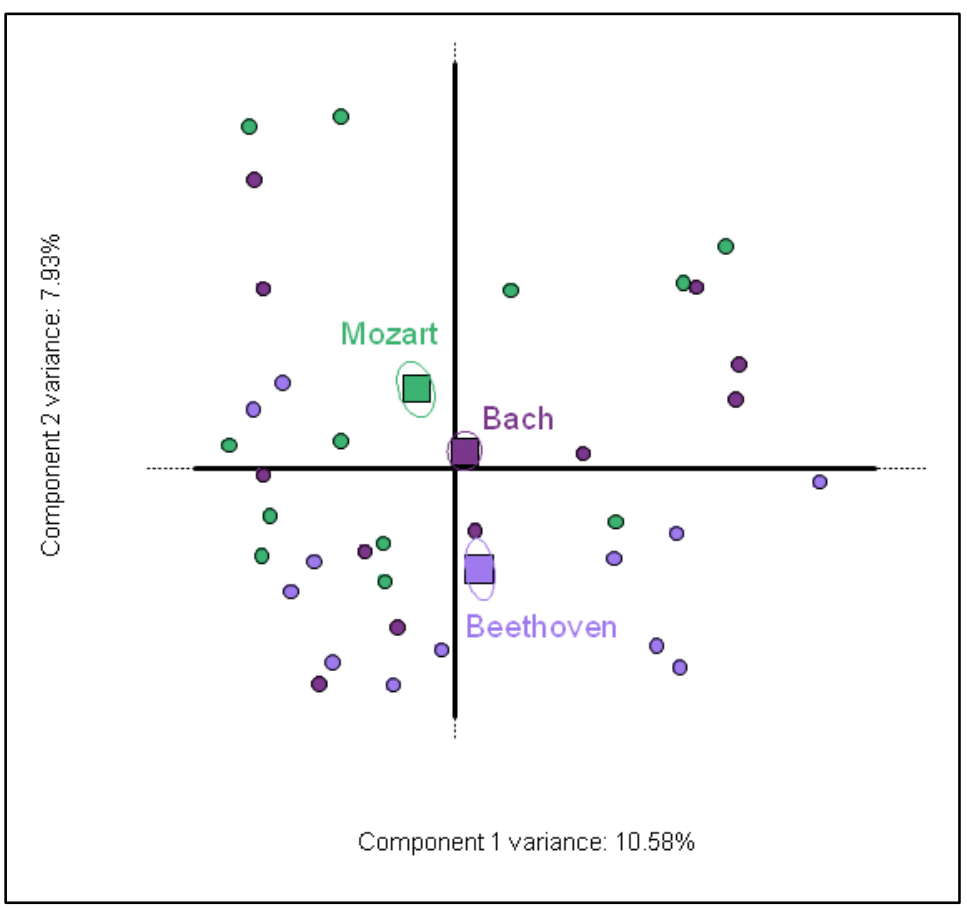

(a)

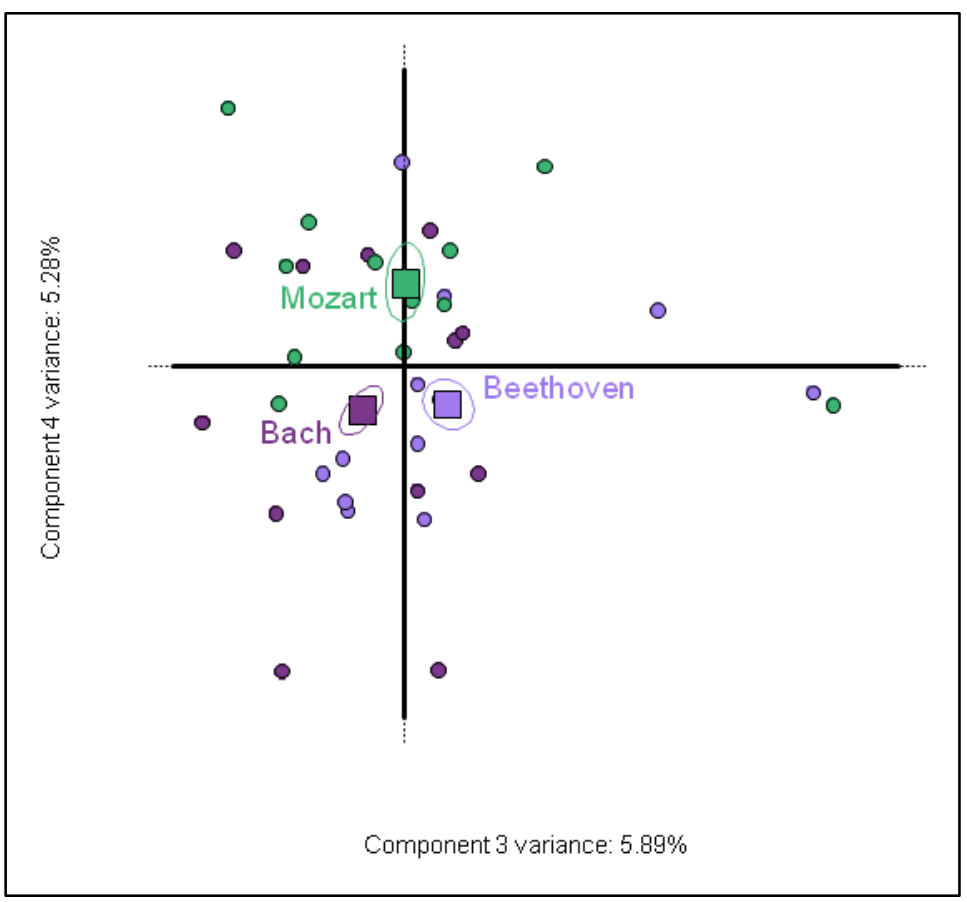

(b) 


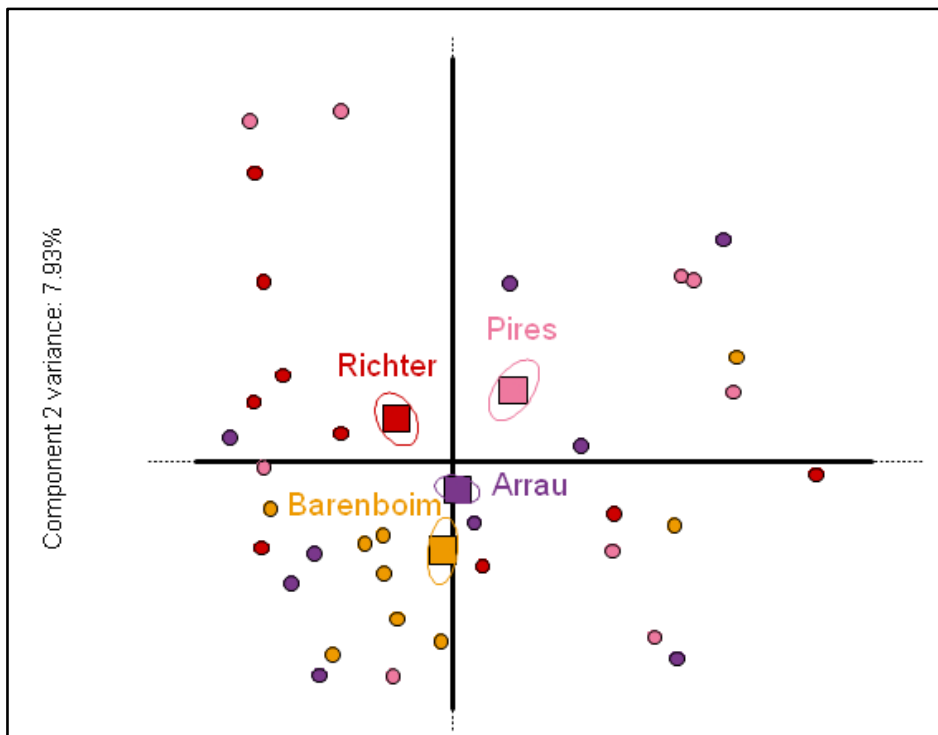

Component 1 variance: $10.58 \%$

1034

1035

1036

1037

1038

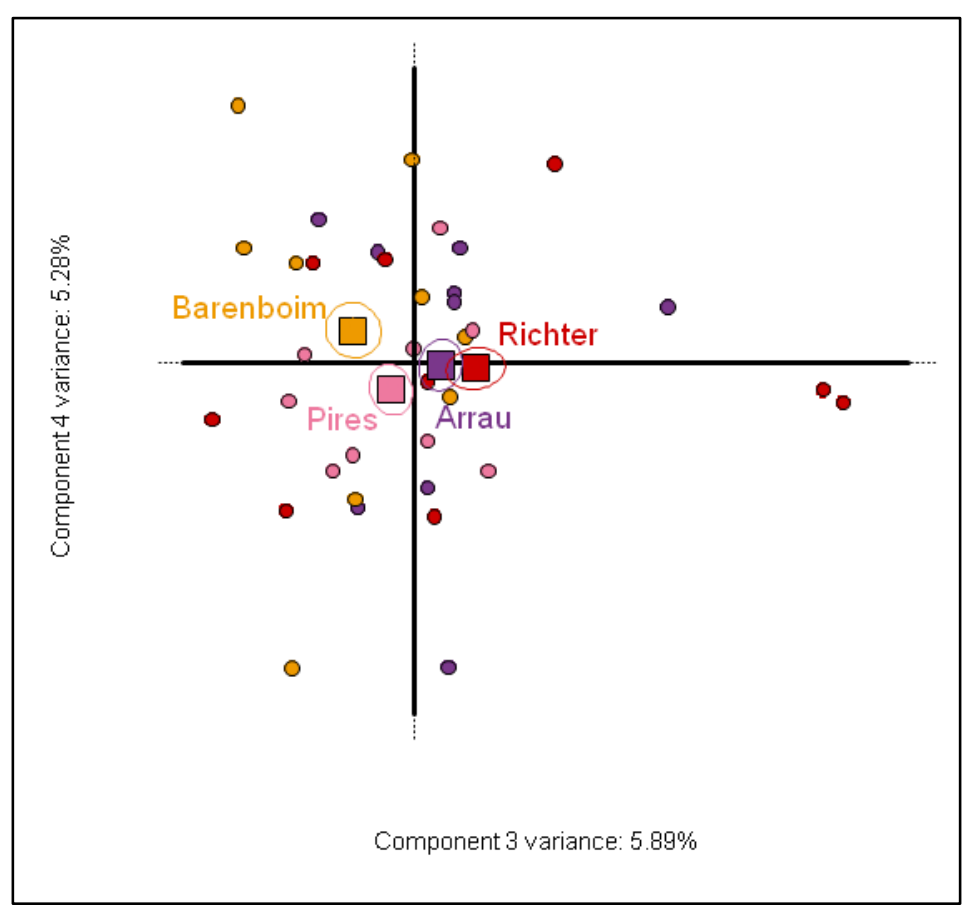

(b)

Figure 6. 


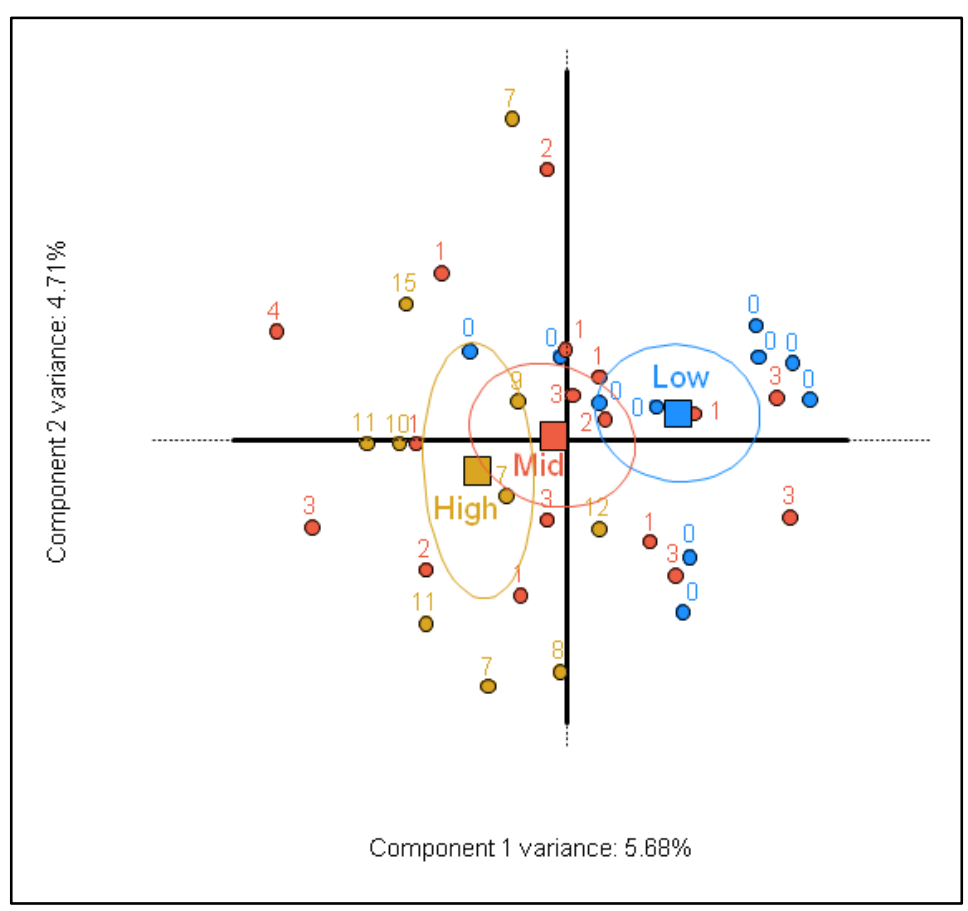

1040

1041

Figure 7.

1042

1043

1044

1045

1046

1047

1048

1049

1050

1051

1052

1053 
(a)

1056

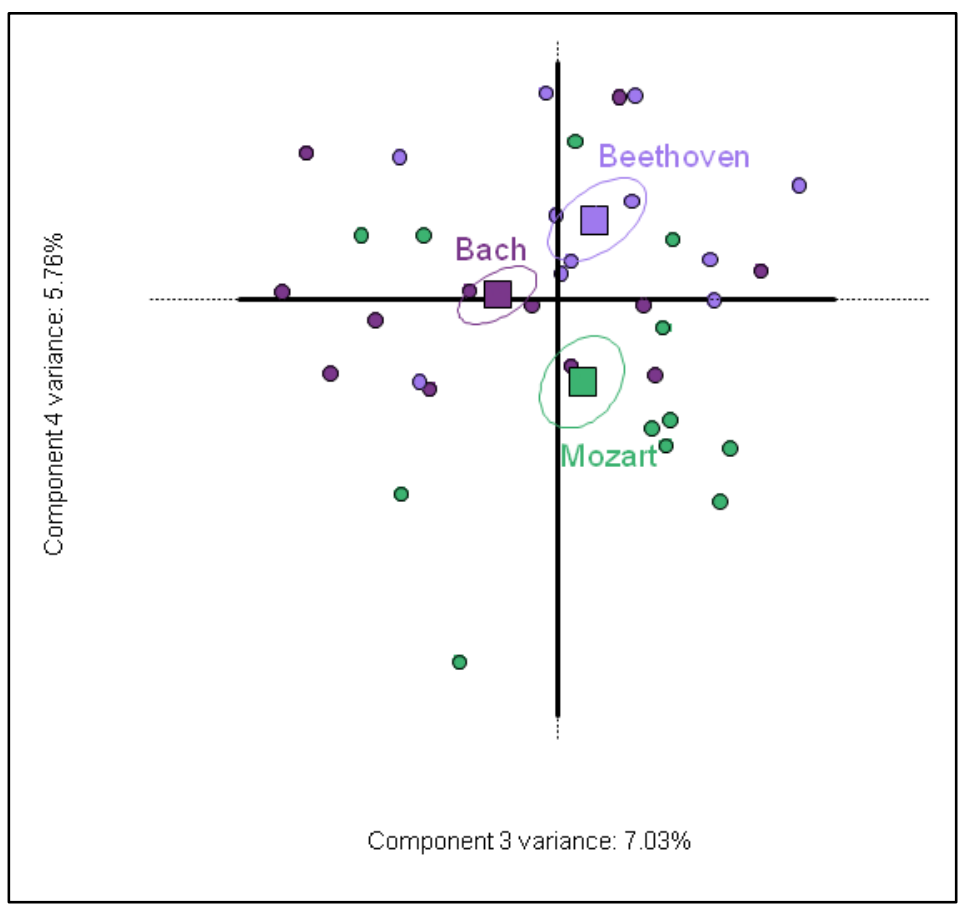

(b)

Figure 8. 
(a)

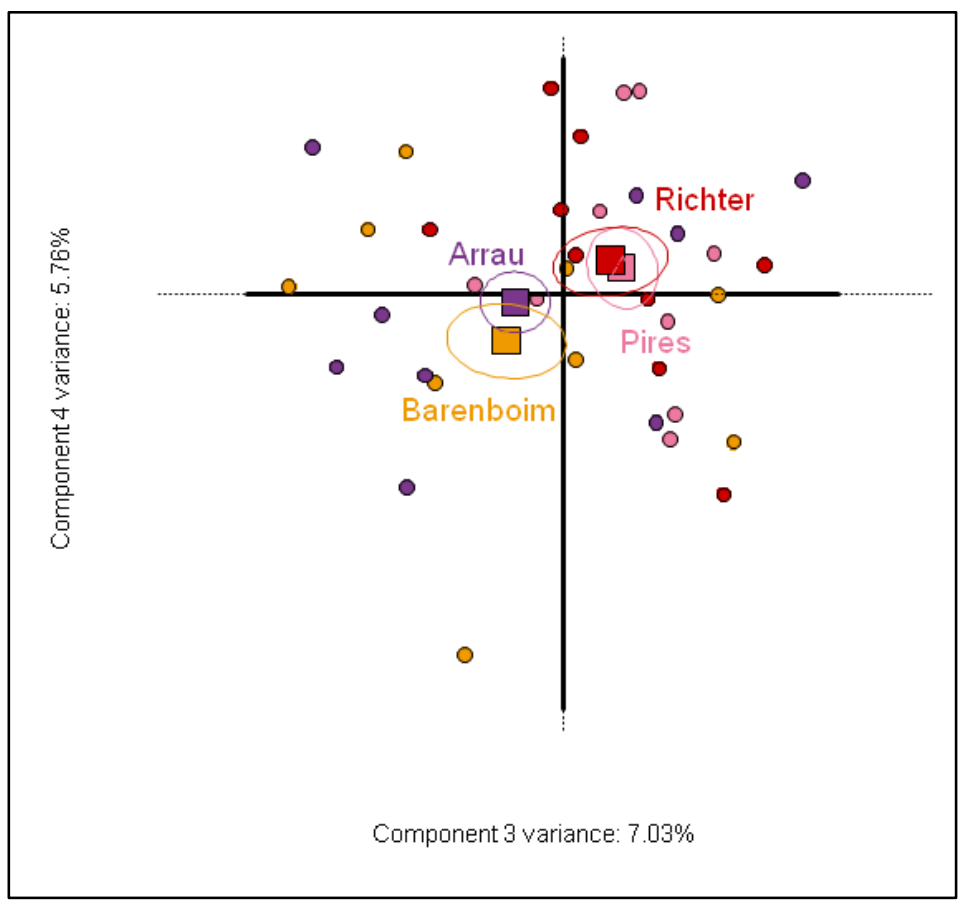

(b)

Figure 9. 


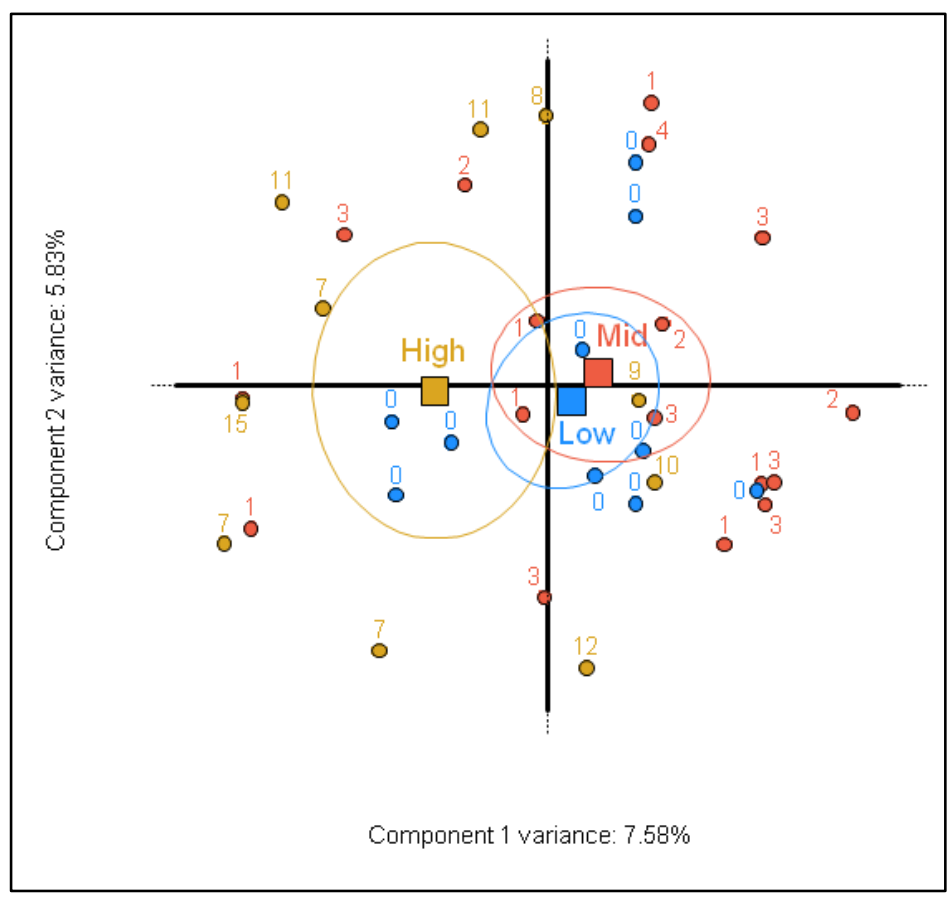

1067

1068

Figure 10.

1069

1070

1071 